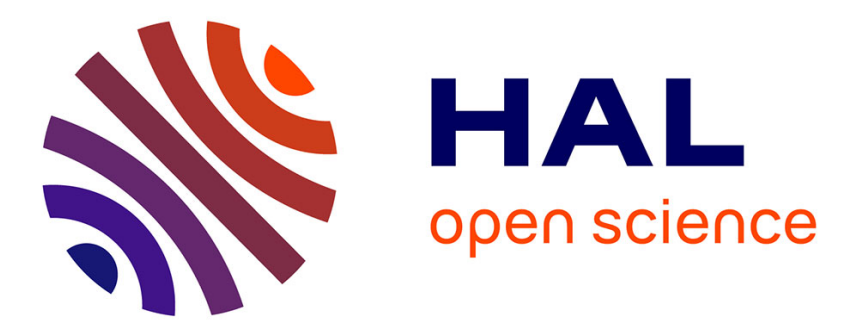

\title{
Amino-grafting of montmorillonite improved by acid activation and application to the electroanalysis of catechol
}

Liliane Dongmo, Sherman L.Z. Jiokeng, Chancellin Pecheu, Alain Walcarius, Ignas Tonle

\section{To cite this version:}

Liliane Dongmo, Sherman L.Z. Jiokeng, Chancellin Pecheu, Alain Walcarius, Ignas Tonle. Aminografting of montmorillonite improved by acid activation and application to the electroanalysis of catechol. Applied Clay Science, 2020, 191, pp.105602. 10.1016/j.clay.2020.105602 . hal-02981476

\section{HAL Id: hal-02981476 \\ https://hal.univ-lorraine.fr/hal-02981476}

Submitted on 26 Nov 2020

HAL is a multi-disciplinary open access archive for the deposit and dissemination of scientific research documents, whether they are published or not. The documents may come from teaching and research institutions in France or abroad, or from public or private research centers.
L'archive ouverte pluridisciplinaire HAL, est destinée au dépôt et à la diffusion de documents scientifiques de niveau recherche, publiés ou non, émanant des établissements d'enseignement et de recherche français ou étrangers, des laboratoires publics ou privés. 
1 Amino-grafting of montmorillonite improved by acid activation and application

2

3

4

5

6

7

8

\section{to the electroanalysis of catechol}

Liliane M. Dongmo ${ }^{\mathrm{a}}$, Sherman L. Z. Jiokeng ${ }^{\mathrm{a}, \mathrm{b}}$, Chancellin N. Pecheu ${ }^{\mathrm{a}}$, Alain Walcarius ${ }^{\mathrm{b}}$ and Ignas K. Tonle $\mathrm{a}^{\mathrm{a}, *}$

${ }^{a}$ Electrochemistry and Chemistry of Materials, Department of Chemistry, University of Dschang, P.O. Box 67 Dschang, Cameroon

${ }^{b}$ Laboratoire de Chimie Physique et Microbiologie pour les Matériaux et l'Environnement (LCPME), UMR 7564 CNRS - Université de Lorraine; 405, rue de Vandoeuvre, 54600 Villers-lès-Nancy, France

\section{Abstract}

In this work, a natural sodium-montmorillonite clay mineral (Mt-Na) was functionalized with amine groups, either by direct grafting $\left(\mathrm{Mt}^{\left.-\mathrm{NH}_{2}\right)}\right.$ or via acid activation followed by grafting $\left(\mathrm{MtH}-\mathrm{NH}_{2}\right)$ of [3(2-aminoethyl)amino)]propyltrimethoxysilane (AEP-TMS). The morphology and structure of the resulting composite materials were characterized by scanning electron microscopy, X-ray diffraction, $\mathrm{N}_{2}$ adsorption-desorption isotherms (BET method) infrared spectroscopy, CHN elemental analysis and thermogravimetric analyses (TGA). The obtained organoclays were then used to modify the surface of a glassy carbon electrode (GCE), and the permselectivity and accumulation properties of the resulting films were investigated by cyclic voltammetry (CV) and electrochemical impedance spectroscopy (EIS). The results indicated that $\mathrm{MtH}-\mathrm{NH}_{2}$ modified GCE (GCE/MtH-NH$\left.{ }_{2}\right)$ exhibited some charge selectivity features and can be applied to the electrochemical oxidation of catechol (CT). By plotting the double logarithmic variation of anodic peak currents (Ipa) versus potential scan rate, the obtained slope value of 0.49 revealed a diffusion-controlled electron-transfer mechanisms for the redox process. The electrochemical behavior of $\mathrm{CT}$ on the modified electrode was also studied using differential pulse voltammetry (DPV). The sensitivities of GCE/MtH-NH $\mathrm{N}_{2}$ for CT were 1.71, 3.87 and 1.35-fold greater than signals obtained on the bare GCE, GCE/Mt-Na and GCE/Mt- $\mathrm{NH}_{2}$ respectively, due to the ability of the aminated materials to strongly accumulate CT. After optimization, GCE/MtH-NH 2 was used for CT determination by differential pulse voltammetry that gave rise to a linear response in the concentration range from $5 \mu \mathrm{M}$ to $80 \mu \mathrm{M}\left(\mathrm{R}^{2}=0.999\right)$, and to a detection limit of $0.65 \mu \mathrm{M}$. The proposed method was applied to CT detection in water samples and in a tea sample.

Keywords: Montmorillonite, Acid activation, Grafting, Organoclays, Electroanalysis, Catechol 


\section{Introduction}

Phenolic compounds are present at low levels in subterranean and drinking waters, as a result of their wide use in textiles, plastics, dyes, paper, herbicides and pesticides (Shan et al., 2009; Lu et al., 2010, Zhao et al., 2012). As environmental pollutants, dihydroxybenzene isomers have been the subject of many studies due to their presence and difficult degradation (Wang et al., 2012). Catechol (CT, 1,2-dihydroxybenzene) is one of the most important phenolic compounds found in teas, vegetables, fruits and tobaccos. Considered as one of the key fragments of tea catechins, CT is contained in tea at various concentrations ranging from 0.1 mg.g $\mathrm{g}^{-1}$ to $0.1 \mathrm{~g} . \mathrm{g}^{-1}$ (Montserrat et al., 2010; Li et al., 2009). Tea also contains proteins, amino acids, alkaloids, carbohydrates, lipoids, organic acids and inorganic elements. CT is of great biological importance with respect to anti-oxidant properties, antivirus and enzyme activities; however, an excessive intake may cause some health problems (Chambers, 1988; Yue et al., 2013). CT is considered as an environmental pollutant by the European Union (EU) (Xie et al., 2006). It is responsible for renal tube degeneration and liver function decrease (Aziz et al., 2007). At low concentration in foods and cigarets, it can cause mutagenesis and cancerous alterations (Hirakawa et al., 2002). Thus, it is critical to establish highly sensitive and selective analytical tools to identify and quantify traces of catechol in environmental samples. Up to now, the most commonly used analytical methods include spectrophotometry (Nagaraja et al., 2001), gas chromatography (Moldoveanu \& Kiser, 2007) and high-performance liquid chromatography (HPLC) (Marrubini et al., 2005). These techniques have some disadvantages, such as complicated operation, poor selectivity and high cost and require highly skilled manpower. Electroanalytical methods may be of interest owning to their sensitivity, rapidity, simplicity and low cost (Fekadu et al., 2013). Thus, some electrochemical methods have been developed for the sensitive detection of CT (Wang et al., 2007; Lin et al., 2009; Zhao et al., 2009, 2012; Yue et al., 2013; Yuan et al., 2013). They are mostly based on the use of chemically modified electrodes, such as anthraquinone modified carbon paste electrode (Fekadu et al., 2013), multi-walled carbon nanotube modified carbon paste electrode (Yongqing et al., 2017) and mesoporous Al-doped silica modified electrode (Lin et al., 2009). The modification of the electrode surface is intended to enhance both sensitivity and selectivity of the detection, but the above examples are based on the use of rather costly modifiers. The development of new composite materials, cheap and easy to prepare, likely to be used as effective electrode modifiers for the sensitive detection of CT is still needed. 
Clay minerals are considered nowadays as interesting adsorbent materials due their low cost, abundance, their morphology ensuring a high surface-to-volume ratio and thus developing large active surface areas. In that context, for instance, Kong et al. (2011) reported a palygorskite modified carbon paste electrode for the determination of CT. However the adsorption capacities and the intrinsic selectivity of natural clays towards organic and inorganic pollutants can be low, restricting the extensive use of these materials (Guggenheim and Martin, 1995). In the aim to get more efficient adsorbents, the elaboration of organicinorganic hybrid materials based on the chemical modification of surface properties of natural clays with organo-functional moieties has become a promising way during the past decades (Tonle et al., 2003, 2005). The so-called organoclays can be obtained by modifying clays and clay minerals with organic groups through several processes: intercalation (or insertion), ion exchange, pillaring or surface grafting (Park et al., 2004; Piscitelli et al., 2010). On the other hand, organoclay modified electrodes have been largely exploited in electroanalysis (Tonle et al., 2015), and most studies reported to date have been focused on layered clay minerals (smectite and kaolinite being the most investigated ones), which can be grafted via the hydroxyl groups localized at the outer surfaces or on the edges of clay particles (for smectitetype clays) or along the unshared plane of the alumina sheets in kaolinite.

In this study, amino-functionalized montmorillonites $\left(\mathrm{Mt}-\mathrm{NH}_{2}\right.$ and $\left.\mathrm{MtH}-\mathrm{NH}_{2}\right)$ have been prepared by grafting [3(2-aminoethyl)]propyltrimethoxysilane (AEP-TMS) on purified clay mineral sample (Mt-Na), then on the same clay sample chemically activated in acid medium $(\mathrm{MtH})$. For $\mathrm{MtH}-\mathrm{NH}_{2}$ material, the acid activation was performed before the grafting process to increase its surface area and enrich its structure with - $\mathrm{OH}$ binding sites (Gonzalez et al., 1984; Rodriguez et al., 1994, Angela de Mello et al. 2009). This may further result in an enhancement of the amount of grafted organosilanes. After characterization of the starting and modified clay materials, it was demonstrated that $\mathrm{MtH}-\mathrm{NH}_{2}$ can be used as prominent modifier for a GCE, and exploited for the preconcentration and sensitive detection of CT in water and tea samples.

\section{Experimental}

\subsection{Clay mineral, materials and chemicals}

The Na-montmorillonite clay mineral used in this work was obtained from the Source Clays Repository, University of Missouri-Columbia (Columbia, MO 65211, USA). The Namontmorillonite has the chemical formula $\mathrm{NaSi}_{16}\left(\mathrm{Al}_{6} \mathrm{FeMg} \mathrm{O}_{20}(\mathrm{OH})_{4}\right.$ (Van Olphen \& 
Fritpiat, 1979). All chemicals were obtained commercially and used without further purification. Catechol $\left(\mathrm{C}_{6} \mathrm{H}_{6} \mathrm{O}_{2}, 99 \%\right.$, Sigma-Aldrich), $\mathrm{H}_{3} \mathrm{BO}_{3}(98 \%$, Fisher Scientific International), $\mathrm{HCl}$ (36\%, Phillip Harris), $\mathrm{CH}_{3} \mathrm{COOH}$ (Prolabo), $\mathrm{KCl}$ (99.5\%, Fisher Scientific International), $\mathrm{H}_{3} \mathrm{PO}_{4}\left(63 \%\right.$, Prolabo), $\mathrm{K}_{2} \mathrm{HPO}_{4}$ (99\% Prolabo), $\mathrm{KH}_{2} \mathrm{PO}_{4}(99 \%$ Prolabo), $\left(\mathrm{CH}_{3} \mathrm{COONa}\right.$ ) (99\% Prolabo), Hexaammineruthenium(III) chloride $\left(\mathrm{Ru}\left(\mathrm{NH}_{3}\right)_{6} \mathrm{Cl}_{3}, 98 \%\right.$, Sigma-Aldrich), and potassium hexacyanoferrate(III) $\left(\mathrm{K}_{3} \mathrm{Fe}(\mathrm{CN})_{6}\right.$, Fluka) served as redox probes for permeability characterization of the film modified electrodes. Various electrolytes such as acetate buffer solution (0.1 M AB), phosphate buffer solution (0.1 M PB), and Britton-Robinson buffer solution (0.1 M BRB) were prepared from the appropriate chemicals mentioned above. The grafting agent ([3-(2-Aminoethylamino)propyl]trimethoxysilane, AEPTMS, $\geq 98 \%$ ) used for clay modification was obtained from Sigma-Aldrich. A tea sample was purchased from local market and treated as follow. Briefly, the tea sample was powdered with a mortar and a weighed portion $(0.055 \mathrm{~g})$ was used for catechol extraction with $50 \mathrm{~mL}$ of $90 \%$ ethanol/water solution for $24 \mathrm{~h}$ shaking at $80^{\circ} \mathrm{C}$. The mixture was filtered and the volume made up to $25.0 \mathrm{~mL}$ for further measurement. All solutions were prepared with distilled water and experiments were carried out at room temperature.

\subsection{Preparation of grafted materials}

Before the grafting process, $1.5 \mathrm{~g}$ of sodium montmorillonite (Mt-Na) was activated with $150 \mathrm{~mL}$ of a $0.1 \mathrm{M} \mathrm{HCl}$ solution. This suspension was stirred for $4 \mathrm{~h}$. Acid activation was used to remove sodium ions from the interlayer region. Then, $1 \mathrm{~g}$ of acid-activated montmorillonite, previously dried at $130^{\circ} \mathrm{C}$ for $4 \mathrm{~h}$, was dispersed in $50 \mathrm{~mL}$ of $0.1 \mathrm{M}$ AEPTMS in dry toluene. The resulting mixture was heated and allowed to reflux under stirring for $72 \mathrm{~h}$ in an inert $\mathrm{N}_{2}$ atmosphere. The solid obtained was washed successively with toluene, ethyl alcohol and then filtered. The product $\mathrm{MtH}-\mathrm{NH}_{2}$ was finally dried for $2 \mathrm{~h}$ at $120^{\circ} \mathrm{C}$ in an inert nitrogen atmosphere and stored in a flask. The same procedure was applied to get Mt$\mathrm{NH}_{2}$, using the purified clay without the acid activation step.

\subsection{Preparation of the working electrodes}

The elaboration of sensors involved the deposition of each organoclay films onto glassy carbon electrode (GCE) surfaces by "drop coating". The GCE was first polished with alumina pastes and then rinsed for $5 \mathrm{~min}$ in a 1:1 water-ethanol mixture under sonication in order to remove any remaining alumina particles. Subsequently, aqueous dispersions of either raw Mt$\mathrm{Na}, \mathrm{Mt}-\mathrm{NH}_{2}$ or $\mathrm{MtH}-\mathrm{NH}_{2}$ (at $5 \mathrm{mg} \cdot \mathrm{mL}^{-1}$ ) were prepared and $6 \mu \mathrm{L}$ (30 $\mu \mathrm{g}$ of clay) were drop- 
coated onto the top of the GCE (surface area: $0.071 \mathrm{~cm}^{2}$ ), which was dried at $110^{\circ} \mathrm{C}$ for 4 min in an oven prior to use. Throughout the text, the modified electrodes are referred to as GCE/Mt-Na, GCE/Mt-NH ${ }_{2}$ and GCE/MtH-NH ${ }_{2}$ for the GCE modified by raw Mt-Na, Mt$\mathrm{NH}_{2}$ and $\mathrm{MtH}-\mathrm{NH}_{2}$, respectively.

\subsection{Electrochemical procedures and apparatus}

Cyclic voltammetry, electrochemical impedance spectroscopy (EIS) and differential pulse voltammetry (DPV) measurements were performed using the palmsens ${ }^{3}$ potentiostat, equipped with the PS Trace 4.2 electrochemical analysis system and connected to a computer. The voltammograms were recorded under quiescent conditions immediately after the immersion of the working electrode in a conventional single compartment cell containing the "analyte + electrolyte" solution, a pseudo reference electrode $\left(\mathrm{Ag} / \mathrm{Ag}^{+}\right)$and a platinum wire auxiliary electrode. Differential pulse voltammetry (DPV) measurements were performed in a $25 \mathrm{~mL}$ electrochemical cell containing 0.1 M Britton-Robinson buffer (BRB) solution ( $\mathrm{pH} 4)$ and catechol at appropriate concentrations, in the potential range from $-0.2 \mathrm{~V}$ to $0.8 \mathrm{~V}$. All experiments were conducted at room temperature $\left(25^{\circ} \mathrm{C}\right)$. EIS were carried out in5mM $\left[\mathrm{Fe}(\mathrm{CN})_{6}\right]^{3-/ 4-}(1: 1)$ solution containing $0.1 \mathrm{M} \mathrm{KCl}$ over the frequency range of $0.1 \mathrm{~Hz}-10$ $\mathrm{kHz}$.The morphology of modified GCEs was analyzed by scanning electron microscopy (SEM) using a JEOL JCM-6000 apparatus (acceleration voltage of $15 \mathrm{kV}$ ). Fourier transform infrared spectroscopy (FTIR) was applied to assess the presence of organic groups in the final materials, using a Nicolet 8700 apparatus equipped with a specular reflectance accessory (Smart Collector). The crystallinity of raw and modified clay materials was determined by Xray diffraction analysis using a Stoe Stadi-p X-ray powder diffractometer (Stoe \& Cie GmbH, Darmstadt, Germany), with $\mathrm{Cu} \mathrm{K \alpha 1}$ radiation $\left(40 \mathrm{kV}, 30 \mathrm{~mA}\right.$ and $\lambda_{\mathrm{Cu}}=1.54056 \AA$ ). The Brunauer-Emmett-Teller (BET) surface areas of the samples were determined by means of $\mathrm{N}_{2}$ adsorption at $77.13 \mathrm{~K}$ using a micrometrics model sorptometer (Thermo Electron Corporation, Sorptomatic Advanced Data Processing). Before $\mathrm{N}_{2}$ adsorption, the samples were degassed at $307.13 \mathrm{~K}$ under vacuum. The surface area was defined from linear part of the BET equation. CHN elemental analysis was performed using CHNS Analyzer Euro EA 3000. The thermal behavior of the clay mineral before and after its modification was investigated by the thermogravimetric analysis (STA $409 \mathrm{C}$ equipment Netzsch Geratebeau $\mathrm{GmbH}$, Germany). Approximately $10 \mathrm{mg}$ of each dried sample were heated from 25 to 1000 ${ }^{\circ} \mathrm{C}$ under nitrogen atmosphere with a heating rate of $10{ }^{\circ} \mathrm{C} / \mathrm{min}$. The $\mathrm{pH}$ of solutions was monitored using an Inolab pH-meter. 


\section{Results and discussion}

\subsection{Physico-chemical characterization of composite materials}

167

168

FTIR spectroscopy was used to identify and compare the functional groups present in natural montmorillonite $(\mathrm{Mt}-\mathrm{Na})$, acid treated $\mathrm{Mt}(\mathrm{MtH})$ and modified montmorillonite $\left(\mathrm{Mt}-\mathrm{NH}_{2}\right.$ and MtH-NH ${ }_{2}$ ) as shown in Fig. 1. On the spectrum of raw clay mineral (Fig. 1a), one can observe a stretching vibration band at $3620 \mathrm{~cm}^{-1}$, which is characteristic of Al-OH stretching of the octahedral sites of natural montmorillonite (Biernacka, 2005), while the bending mode of such hydroxyl groups appears at $916 \mathrm{~cm}^{-1}$ (Qin et al., 2010). The peaks observed at 3404 and 1640 $\mathrm{cm}^{-1}$ are attributed to the $-\mathrm{OH}$ stretching and bending vibrations of physisorbed water in the interlamellar space of montmorillonite, respectively. Others observed bands, appearing on all investigated materials between 700 and $450 \mathrm{~cm}^{-1}$ correspond to Si-O-Si stretching $\left(690 \mathrm{~cm}^{-1}\right)$ and deformation (516 and $468 \mathrm{~cm}^{-1}$ ) of tetrahedral sites (Mendelovici, 1973). The signals at 885,843 and $777 \mathrm{~cm}^{-1}$ are due to $\mathrm{Al}-\mathrm{OH}$ deformation, $\mathrm{Fe}-\mathrm{OH}$ deformation and $\mathrm{Mg}-\mathrm{OH}$ deformation respectively (Amarasinghe et al., 2008; Katti et al., 2006). After acid activation, some changes in the FTIR spectra (Fig. 1b) can be observed. The band intensity at 3620 and $1640 \mathrm{~cm}^{-1}$ increased slightly, thus suggesting that the $\mathrm{MtH}$ sample is more hydrophilic than the Mt-Na. The appearance of a shoulder around $3150 \mathrm{~cm}^{-1}$ traduces the presence of Si-OH groups arising upon $\mathrm{Si}-\mathrm{O}-\mathrm{Al}$ bonds breaking during the acid pretreatment. The $\mathrm{OH}$ stretching region of $\mathrm{Mt}$ is sensitive to the effects of interlayer modification, and the intercalation followed by the grafting of the organosilane on the internal surface $-\mathrm{OH}$ groups of $\mathrm{MtH}$ should have a major influence on the $\mathrm{OH}$ stretching pattern of the grafted organoclays. As a matter of fact, upon grafting of AEP-TMS, some pronounced changes occurred in the spectra of amino-montmorillonite clays samples $\left(\mathrm{Mt}-\mathrm{NH}_{2}\right.$ and $\left.\mathrm{MtH}-\mathrm{NH}_{2}\right)$ (Fig. 1c and 1d): the new absorption band at $2928 \mathrm{~cm}^{-1}$ is due to the antisymmetric stretching of $-\mathrm{CH}_{2}$ bonds (Qin et al., 2010, Xue et al., 2011, ) while the bands appearing at $1473 \mathrm{~cm}^{-1}$ and $1316 \mathrm{~cm}^{-1}$ are assigned to $-\mathrm{CH}_{2}$ - scissoring deformation (symmetric and asymmetric respectively), both from the silane coupling agent. The symmetric stretching of $-\mathrm{CH}_{2}$ bonds are also visible at $2840 \mathrm{~cm}^{-1}$ (Qin et al., 2010). Comparing curves (c) \& (d) of Figure 1 enables to point out qualitatively the interest of the acidic treatment on the efficiency of the functionalization (slightly more intense $\mathrm{C}-\mathrm{H}$ bond for the $\mathrm{MtH}-\mathrm{NH}_{2}$ sample). The grafting process leads to a decrease in the intensity of the bands characteristics of $\mathrm{OH}$ stretching and bending vibrations of adsorbed water and the hydroxyl groups (respectively at 3404 and $1640 \mathrm{~cm}^{-1}$ ) and a very small deviation of the positions of these bands. This is due in one hand to the involvement of the hydroxyl groups in 
the grafting process, and in another hand to the removal of cations from the octahedral layer which causes some loss of water molecules.

(Figure 1 near here)

XRD patterns of raw Mt-Na, acid treated $\mathrm{Mt}(\mathrm{MtH}), \mathrm{Mt}-\mathrm{NH}_{2}$ and $\mathrm{MtH}-\mathrm{NH}_{2}$ are shown in Fig. 2. A comparison of the results obtained indicates that the original structure has been retained after modification. An approximate value of $1.21 \mathrm{~nm}\left(2 \theta=7.3^{\circ}\right)$ was estimated for the basal spacing $\mathrm{d}_{001}$ of the Mt-Na sample (Fig. 2A, curve a). The acid activation led to an increase in the basal spacing (1.21 to $1.30 \mathrm{~nm})$, most likely due to water adsorption. The increased hydrophilic feature of the $\mathrm{MtH}$ (Fig. 2A, curve b) with respect to the starting Mt was previously indicated by the IR results. Direct grafting of AEP-TMS onto Mt-Na showed a minimal difference in basal spacing between the Mt-Na and $\mathrm{Mt}-\mathrm{NH}_{2}$ samples (1.21 nm to 1.36 $\mathrm{nm}$ at $2 \theta=6.5^{\circ}$ ) (Fig. 2A, curve c). This slight difference is probably due to a small amount of AEP-TMS in the interlamellar space of the clay mineral. Usually, the intercalation of guest species in montmorillonite layers induces significant changes in the basal spacing (Mercier \& Detellier, 1995). The acid activation used in $\mathrm{MtH}-\mathrm{NH}_{2}$ synthesis resulted in a much bigger increase in the basal spacing of the $\mathrm{MtH}$ and $\mathrm{MtH}-\mathrm{NH}_{2}$ samples $(1.30 \mathrm{~nm}$ to $1.80 \mathrm{~nm}$ ) (Fig. 2A, curve c), probably due to AEP-TMS incorporated in basal spacing. It may indicate that the silane molecules were mainly hydrolyzed and condensed with the hydroxyl groups on the external surface of Mt. Another explanation could be that the interlayer organosilane molecules were hydrolyzed and condensed to form a cross-linked structure, causing small increase on the basal spacing and influencing the grafting of AEP-TMS on MtH. The TGA curves (Fig. 2B) revealed a significant increase in the loss of adsorbed water mass on the MtH (Fig. 2B, curve b) compared to raw Mt (Fig. 2B, curve a). Usually, the increase in water content leads to an increase in the basal spacing. This increase in water molecules is explained by the replacement of sodium ions in the interlayer space by water molecules. On the materials $\mathrm{Mt}_{-} \mathrm{NH}_{2}$ (Fig. 2B, curve c) and $\mathrm{MtH}-\mathrm{NH}_{2}$ (Fig. 2B, curve d), the mass losses of absorbed water are comparable to that of the raw clay. Our hypothesis is that for the Mt- $\mathrm{NH}_{2}$ sample, the organosilane was grafted on the surface without replacement of sodium ions while for the $\mathrm{MtH}-\mathrm{NH}_{2}$, there was replacement of water molecules in the interlayer space of $\mathrm{MtH}$ and grafting on the surface. 
231 Elemental analysis was performed on the amino-grafted materials $\left(\mathrm{Mt}-\mathrm{NH}_{2}\right.$ and $\left.\mathrm{MtH}-\mathrm{NH}_{2}\right)$

232 for $\mathrm{C}, \mathrm{H}$ and $\mathrm{N}$. The results obtained were $11.07 \% \mathrm{C}, 2.60 \% \mathrm{H}, 4.66 \% \mathrm{~N}$ for $\mathrm{Mt}_{-} \mathrm{NH}_{2}$ and $2339.73 \% \mathrm{C}, 2.44 \% \mathrm{H}, 3.89 \% \mathrm{~N}$ for $\mathrm{MtH}-\mathrm{NH}_{2}$. This was evidence of the presence of nitrogen234 containing moieties. To determine the structural formula of the grafted clay using the the 235 chemical formula of $\mathrm{Mt}, \mathrm{NaSi}_{16}\left(\mathrm{Al}_{6} \mathrm{FeMg}\right) \mathrm{O}_{20}(\mathrm{OH})_{4}$, we assumed grafting via one, two, three

(a)
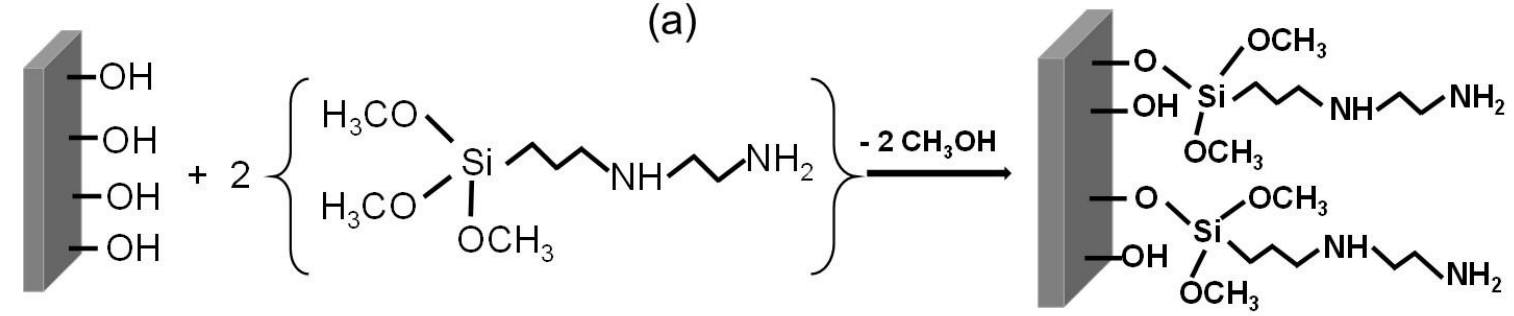

(b)
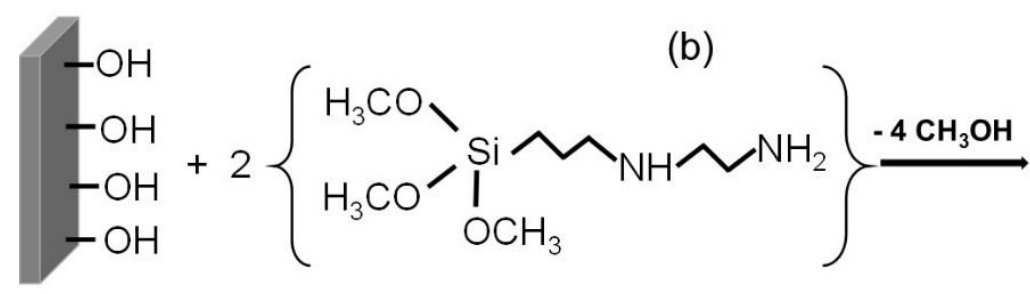

were $\mathrm{NaSi}_{16}\left(\mathrm{Al}_{6} \mathrm{FeMg}\right) \mathrm{O}_{20}(\mathrm{OH})_{2}\left[\mathrm{OSi}\left(\mathrm{OCH}_{3}\right)_{2}\left(\mathrm{CH}_{2}\right)_{3} \mathrm{NH}\left(\mathrm{CH}_{2}\right)_{2} \mathrm{NH}_{2}\right]_{2}$ and $\mathrm{Si}_{16}\left(\mathrm{Al}_{5} \mathrm{FeMg}\right) \mathrm{O}_{21}(\mathrm{OH})_{3}\left[\mathrm{O}_{2} \mathrm{Si}\left(\mathrm{OCH}_{3}\right)\left(\mathrm{CH}_{2}\right)_{3} \mathrm{NH}\left(\mathrm{CH}_{2}\right)_{2} \mathrm{NH}_{2}\right]_{2}$ respectively. An increase in SiOHs bonds and a decrease in the number of $\mathrm{Al}$ can be observed in the $\mathrm{MtH}-\mathrm{NH}_{2}$ formula compared to $\mathrm{Mt}-\mathrm{NH}_{2}$ formula. These increase and decrease occurred during the acid pretreatment by $\mathrm{Si}-\mathrm{O}-\mathrm{Al}$ bonds breaking during the removal of $\mathrm{Al}$. 
-OH groups at the edge of clay platelets, as shown by a previous work (Celis et al., 2000). It is known that the low silanol surface density of montmorillonite clay mineral is a main factor limiting the covalent grafting of organic ligands and that better performance can be obtained by grafting organic functions in the interlayer region of montmorillonite (Celis et al., 2000; Mercier and Detellier, 1995). Another sample of sodium montmorillonite was activated in acid medium $(\mathrm{MtH})$ and then functionalized $\left(\mathrm{MtH}-\mathrm{NH}_{2}\right)$. A specific surface area of 19.66 $\mathrm{m}^{2} / \mathrm{g}$ obtained for the MtH-NH 2 material suggests a low graft rate on the surface of the material but the increase in basal spacing obtained in XRD analysis from $1.36 \mathrm{~nm}\left(\mathrm{Mt}-\mathrm{NH}_{2}\right)$ to $1.80 \mathrm{~nm}\left(\mathrm{MtH}-\mathrm{NH}_{2}\right)$ confirms the intercalation followed by the concomitant coupling of the organosilane moieties on the $-\mathrm{OH}$ groups found the internal surface of on the clay layers, and on the borders of the clay platelets.

SEM micrographs of the GCE modified in turn by Mt-Na, acid treated Mt (MtH), Mt- $\mathrm{NH}_{2}$ and $\mathrm{MtH}-\mathrm{NH}_{2}$ respectively are shown in Fig. 3. On the micrographs of GCE/Mt-Na and GCE/MtH (Fig. 3a \& 3b), one can observe the strong tendency toward aggregation and the compact aspect of the material, with particles arranged in the form of agglomerates of irregular shape and flat surface. For the Mt- $\mathrm{NH}_{2}$ and $\mathrm{MtH}-\mathrm{NH}_{2}$ modified GCEs (Fig. $3 \mathrm{c} \& 3 \mathrm{~d}$ ), the particles are even more agglomerated and present onto the electrode surface as big aggregates, suggesting that the functionalization of clay may have contributed to enhance the edge-to-edge and face-to face interactions between organoclay platelets.

\section{(Figure 3 near here)}

\subsection{Permeability properties of various modified electrodes}

The electrochemical behavior of redox species at clay modified electrodes is expected to be affected by three main parameters: the concentration of the analyte, the accessible area of the working electrode and the speed of mass transfer for the probe within the film (Fitch, 1990). Cyclic voltammetry (CV) was applied to the modified electrodes to evaluate their preconcentration/rejection properties or permselective behavior towards $\left[\mathrm{Fe}(\mathrm{CN})_{6}\right]^{3-}$ and $\left[\mathrm{Ru}\left(\mathrm{NH}_{3}\right)_{6}\right]^{3+}$ electroactive probes. $\mathrm{CV}$ experiments were performed using the bare GCE, GCE/Mt-Na, GCE/Mt- $\mathrm{NH}_{2}$ and GCE/MtH-NH $\mathrm{NH}_{2}$ in $0.1 \mathrm{M} \mathrm{KCl} / \mathrm{HCl}$ solution at $\mathrm{pH} 1$. Both probes gave rise to well defined reversible CV responses at on the bare GCE (curves (a) in Figure $4(\mathrm{~A}) \&(\mathrm{~B}))$. The peak current values obtained are $\mathrm{I}_{\mathrm{pa}} 3.06 \mu \mathrm{A}$ (anodic), $\mathrm{I}_{\mathrm{pc}} 2.9 \mu \mathrm{A}$ 
(cathodic) and $\mathrm{I}_{\mathrm{pa}} 1.46 \mu \mathrm{A}$ (anodic), $\mathrm{I}_{\mathrm{pc}} 1.95 \mu \mathrm{A}$ (cathodic), respectively for $\left[\mathrm{Fe}(\mathrm{CN})_{6}\right]^{3-}$ and $\left[\mathrm{Ru}\left(\mathrm{NH}_{3}\right)_{6}\right]^{3+}$ probes, and they did not change upon multiple potential scanning. This was not the case when recording multisweep CV curves at the clay-modified electrodes. Typical results obtained for $0.5 \mathrm{mM}\left[\mathrm{Fe}(\mathrm{CN})_{6}\right]^{3-}$ probe (in the potential range of $0.0 \mathrm{~V}$ to $0.6 \mathrm{~V}$ ) are illustrated in Fig. S1 (Supplementary data). On Fig. S1a, one can see that the voltammetric signal on the GCE/Mt-Na is constant over multiple potential scans, the peak currents values (Ipa1.30 $\mu$ A, Ipc $1.27 \mu \mathrm{A}$ ) lower than those obtained at the bare. Such behavior is explained by the electrostatic repulsions between the negative surfaces of Mt-Na and the anionic probe $\left[\mathrm{Fe}(\mathrm{CN})_{6}\right]^{3-}$ (Tonle et al., 2004). On the opposite, CV signals were found to grow dramatically upon multisweep scan when using the amino-montmorillonite modified GCE (Fig. S1 b \& c), indicating the progressive accumulation of $\left[\mathrm{Fe}(\mathrm{CN})_{6}\right]^{3-}$ that leveled off after about 50 scans, with steady-state peak current values larger by one order of magnitude than on bare GCE (Fig. 4A). Such accumulation is due to the electrostatic attraction between the negative redox probe $\left[\mathrm{Fe}(\mathrm{CN})_{6}\right]^{3-}$ and the positively charged amino groups present in the AEP-TMS chain grafted onto the montmorillonite surface (which are protonated in the acidic analysis medium used here, in the form of $-\mathrm{NH}_{3}{ }^{+}$groups). As also shown in Fig. 4A, the electrochemical signal after 50 scans on GCE/MtH-NH 2 (Ipa $22.22 \mu \mathrm{A}$, Ipc $23.66 \mu \mathrm{A}$ ) is significantly higher than those obtained on GCE/Mt-NH 2 (Ipa $14.79 \mu \mathrm{A}$, Ipc $17.74 \mu \mathrm{A}$ ). This difference is due to a larger content of AEP-TMS groups grafted onto the acid-treated montmorillonite.

Cyclic voltammetry of cationic probe $\left[\mathrm{Ru}\left(\mathrm{NH}_{3}\right)_{6}\right]^{3+}$ (Fig. S2 in Supplementary data) was also carried out in the potential range of $-0.5 \mathrm{~V}$ to $0.0 \mathrm{~V}$ in the same electrolyte solution as above (0.1 M KCl/HCl, pH 1). For GCE coated with $\mathrm{Mt}-\mathrm{Na}$, a progressive accumulation was observed, reaching steady-state current values after about 50 scans (Fig. S2a). The peak currents at saturation (Ipa $19.33 \mu \mathrm{A}$, Ipc $18.06 \mu \mathrm{A}$ ) were much larger than those obtained at the bare GCE (Ipa $1.46 \mu \mathrm{A}$, Ipc $1.95 \mu \mathrm{A}$ ), as explained by favorableelectrostatic attraction between the cationic redox probe and the negatively charged montmorillonite platelets. This behavior results from both true physical diffusion of the analyte upon ion exchange in the coating, and mass-charge transfer phenomena arising from potential scanning (Tonle et al., 2004). On the opposite, when using GCE/Mt-NH $\mathrm{NH}_{2}$ and GCE/MtH-NH 2 in the same conditions (Fig. S2 b \& c), the protonated organoclay films acted as electrostatic barrier preventing the uptake of the cationic $\left[\mathrm{Ru}\left(\mathrm{NH}_{3}\right)_{6}\right]^{3+}$ species. This resulted in much lower redox peak currents on GCE/Mt-NH 2 (Ipa 3.81 $\mu \mathrm{A}$, Ipc $4.81 \mu \mathrm{A})$ and GCE/MtH-NH $2($ Ipa $2.21 \mu \mathrm{A}$, Ipc $3.62 \mu \mathrm{A})$ than for the non-grafted clay film electrode GCE/Mt-Na (Fig. 4B), as explained by the electrostatic repulsions between the positively charged redox probe and the $-\mathrm{NH}_{3}{ }^{+}$groups of 
the organoclays. Again, the permselective effect was more intense for GCE/MtH- $\mathrm{NH}_{2}$ electrode, supporting the idea that acid activation prior to AEP-TMS grafting resulted in more effective montmorillonite modification.

(Figure 4 near here)

\subsection{EIS results}

Electrochemical impedance spectroscopy (EIS) was used to evaluate the electrochemical properties of the various electrodes. In EIS, the semicircle portion at higher frequencies corresponds to the electron-transfer limited process (equals the charge-transfer resistance, $\mathrm{R}_{\mathrm{ct}}$ ), and the linear part at lower frequencies corresponds to the diffusion process. Fig. 5 shows the Nyquist plots of EIS for the bare GCE, GCE/Mt-Na, GCE/Mt-NH $\mathrm{N}_{2}$ and GCE/MtH$\mathrm{NH}_{2}$ electrodes, as recorded in $0.1 \mathrm{M} \mathrm{KCl}$ containing $5 \mathrm{mM}\left[\mathrm{Fe}(\mathrm{CN})_{6}\right]^{3-/ 4-}(1: 1)$ solution over the frequency range of $0.1 \mathrm{~Hz}-10 \mathrm{kHz}$. At the bare GCE (curve (a) in Fig. 5), the probe is easy to transfer electron on the electrode surface, yet with a non-negligible $R_{c t}$ value of $4736 \Omega$. The charge-transfer resistance was even larger $\left(\mathrm{R}_{\mathrm{ct}}=5263 \Omega\right)$ when using GCE/Mt-Na (curve (b) in Fig. 5), which is explained by some shielding behavior of the positively charged Mt clay particles on the anionic $\left[\mathrm{Fe}(\mathrm{CN})_{6}\right]^{3-/ 4-}$ species. With the grafting of AEP-TMS on Mt-Na, the resistance decreased (see curves (c) and (d) of Fig. 5), implying that $\mathrm{Mt}^{-\mathrm{NH}_{2}}$ and $\mathrm{MtH}-$ $\mathrm{NH}_{2}$ promote the transport properties of the $\left[\mathrm{Fe}(\mathrm{CN})_{6}\right]^{3-/ 4-}$ probes. This resulted in lower $\mathrm{R}_{\mathrm{ct}}$ values $\left(\mathrm{R}_{\mathrm{ct}}=114.35 \Omega\right.$ with GCE/MtH-NH${ }_{2}$ and $\mathrm{R}_{\mathrm{ct}}=167.84 \Omega$ with GCE/Mt-NH$)$, the small difference between them being again due to the fact that acid activation allowed the binding of a greater amount of AEP-TMS moieties on the Mt clay.

(Figure 5 near here)

\subsection{Preliminary studies on the electrochemical behavior of catechol}

\subsubsection{Direct electrochemistry of catechol}

The electrochemical behaviour of catechol on various electrodes was carried out in $0.1 \mathrm{M}$ Britton-Robinson buffer (BRB) solution at $\mathrm{pH} 4$ in the potential range from $-0.2 \mathrm{~V}$ to $0.8 \mathrm{~V}$, and the results are shown in Fig. 6. A pair of quasi-reversible redox peaks are observed on all $\mathrm{CV}$ curves, indicating that the electroactive substance can reach and be detected on all electrode surfaces. Nevertheless, significant variations in peak intensity were observed 
352

353

354

355

356

357

358

359

360

361

362

363

364

365

366

367

368

369

370

371

372

373

374

375

376

377

378

379

380

381

382

depending on the electrode type. Peak currents were almost 2-fold lower on GCE/Mt-Nathan on bare GCE (curves(a) \& (b) on Fig. 6), whereas significantly more intense signals were observed when passing to GCE modified by amino-grafted materials (curves(c) \& (d) on Fig. 6). This indicates the interest of the amino-grafted materials for enhancing the CT oxidation signal, suggesting the existence of accumulation effects originating from the grafted material, which are likely to improve the detection of $\mathrm{CT}$, yet with slightly better response for GCE/MtH-NH 2 than for GCE/Mt-NH2 (compare curves (c) \& (d) on Fig. 6). This demonstrates the interest of the acid activation used during the grafted process to prepare $\mathrm{MtH}-\mathrm{NH}_{2}$ material, and also for CT detection. Such improvement is similar to that observed for the negatively charged redox probe discussed above (Fig. 4A), but in the present case "simple" electrostatic considerations cannot explain the phenomenon as catechol is neutral at pH values below its pKa (9.14) (Nurchi et al., 2009), and deprotonated at pH above that pKa. The CV results indicate a clear positive effect of the ethylenediamino groups grafted on the clay material, and this was also confirmed for CT detection by DPV (see section 3.5.1). A possible explanation could be a favoured incorporation of CT in the organoclay as a result of larger interlayer distance between the clay sheets upon grafting (see section 3.1 and Fig. 2) and also a more hydrophobic environment generated by the acidic treatment (in comparision to the hydrophilic Mt-Na material). The $\mathrm{O}$ and $\mathrm{N}$ groups of $\mathrm{Mt}-\mathrm{NH}_{2}$ and $\mathrm{MtH}-\mathrm{NH}_{2}$ acted as electron transfer mediators by possibly forming hydrogen bonding interactions with hydroxyl groups of CT. They have contributed to weakening the hydroxyl bond energies and facilitated the electron transfer through O- -HO and N- -HO (Ding et al., 2005).

The Mt- $\mathrm{NH}_{2}$ and $\mathrm{MtH}-\mathrm{NH}_{2}$ modifiers might also contribute to accelerate the electron transfer ratesfor catechol oxidation, as suggested from slightly lower overpotentials with respect to bare GCE (compare peak potentials of curves c \& d to curve a in Fig. 6), also in agreement with the much lower charge transfer resistance values observed by EIS for the modified electrodes (see section 3.3). Due to its better performance with respect to CT detection, the $\mathrm{GCE} / \mathrm{MtH}-\mathrm{NH}_{2}$ electrode was used for further experiments.

\section{(Figure6 near here)}

\subsubsection{Effect of scan rate on the electrochemical response of catechol at GCE/MtH-NH}


The influence of potential scan rate on the electrochemical response of catechol was studied by cyclic voltammetry and the results obtained are shown in Fig. 7. The peak currents increased with the scan rate in the studied range (Fig. 7a), remaining linear with the square root of the scan rate $\left(\mathrm{v}^{1 / 2}\right)$ (Fig. 7b). This indicates a diffusion-controlled process, phenomenon that was also confirmed by plotting the double logarithmic of Ipa vs scan rate (Fig. 7c), giving a slope $(\partial \log (\operatorname{Ipa}) / \partial \log (\mathrm{v}))$ equal to 0.49 , close to 0.5 , the characteristic value for a diffusion-controlled electron-transfer mechanism (Shih et al., 2004).

(Figure 7 near here)

\subsection{Differential pulse voltammetry study}

\subsubsection{Importance of the modification of Mt and effect of the detection medium}

In order to evaluate the ability of AEP-TMS grafted Mt to accumulate quantitatively CT and the interest of the acid activation step before grafting, DPVs of $0.1 \mathrm{mM}$ CT were recorded in 0.1 M BRB solution (pH 4) on bare GCE, GCE/Mt-Na, GCE/Mt-NH ${ }_{2}$ and GCE/MtH-NH (Fig. 8). Peak currents were found to decrease from the bare GCE $(1.7 \mu \mathrm{A})$ to GCE/Mt-Na $(0.75 \mu \mathrm{A})$, and increase when passing from GCE/Mt-Na $(0.75 \mu \mathrm{A})$ to GCE/Mt-NH $2(2.15 \mu \mathrm{A})$ and to GCE/MtH-NH $\mathrm{NH}_{2}(2.9 \mu \mathrm{A})$. Meanwhile, the peak potentials shifted towards less anodic values: from $+0.358 \mathrm{~V}$ on bare GCE to $+0.271 \mathrm{~V}$ on GCE/Mt-Na, to $+0.270 \mathrm{~V}$ on GCE/Mt$\mathrm{NH}_{2}$ and to $+0.260 \mathrm{~V}$ on GCE/MtH-NH . This indicates an the ability of Mt- $\mathrm{NH}_{2}$ and MtH$\mathrm{NH}_{2}$ to induce effective enhancement of CT oxidation signal and improve the electron transfer rates, confirming the existence of both accumulation and electrocatalytic effects as suggested above, originating from the organoclay materials with respect to the detection of CT. Note that acid activation improved somewhat further the electrochemical detection of CT by increasing the current peak signal.

\section{(Figure 8 near here)}

Some optimization studies were also performed. Although the composition of the detection medium was not really critical (on the basis of three different buffer solutions), the BRB solution ( $\mathrm{pH} 4$ ) was found to be more sensitive to CT detection (see Fig. S3, Supplementary 
data). It will be thus used for further experiments. Fig. S4 (Supplementary data) shows the dependence of DPV peak currents on the accumulation time for the analysis of $0.1 \mathrm{mM} \mathrm{CT}$ at GCE/MtH-NH 2 electrode. The response was very fast, and the electrode was saturated after $30 \mathrm{~s}$, reaching a plateau up to $140 \mathrm{~s}$ preconcentration. Fast adsorptive equilibrium is probably due to low resistance to mass transport in such highly porous film electrode. A duration of 30 $\mathrm{s}$ was used afterwards for the accumulation of CT.

\subsubsection{Influence of $\mathrm{pH}$ on the peak current and potential}

The influence of the $\mathrm{pH}$ of the detection medium on the electrochemical response of CT was studied in the range from 2 to 8 in BRB solution. Fig. 9a and curve (2) on Fig. 9b show that the oxidation peak potentials of $\mathrm{CT}$ on GCE/MtH- $\mathrm{NH}_{2}$ shifted negatively with an increase in the solution $\mathrm{pH}$, indicating that protons are involved in the reaction process at the electrode surface. The linear regression equation was $\operatorname{Ep}(\mathrm{V})=-0.0521 \mathrm{pH}+0.4819\left(\mathrm{R}^{2}=0.998\right)$, demonstrating that equal number of electrons and protons are involved in the oxidation of CT. This is in agreement with the previously reported mechanism for CT, that is oxidized to 1,2benzoquinone (Scheme 2) (Temerk et al., 2006; Unnikrishnan et al., 2012; Yue et al., 2013). Curve (1) on Fig. 9b shows the variation of the peak current of $\mathrm{CT}$ with $\mathrm{pH}$. The peak intensity was high in acidic media, for $\mathrm{pH}$ values below 5 , with a maximum at $\mathrm{pH} 2$. The electrode response became less pronounced in basic media. The preconcentration of CT was more effective in acidic media on GCE/MtH-NH experiments.<smiles>Oc1ccccc1O</smiles>

Catechol<smiles>O=C1C=CC=CC1=O</smiles>

1,2-benzoquinone

Scheme 2. Mechanism of catechol oxidation

(Figure 9 near here)

\subsubsection{Calibration}


The calibration graph for CT detection was plotted from DPV analyses performed under the optimal conditions obtained above, in the concentration range from $5 \mu \mathrm{M}$ to $80 \mu \mathrm{M}$, using the GCE/MtH-NH 2 electrode. As shown by the inset in Fig. 10, a linear variation of peak current (Ip) vs CT concentration was obtained in the explored range, with a sensitivity of 0.0468 $\mu \mathrm{A} . \mu \mathrm{M}^{-1}$ and a correlation coefficient of 0.999 . The detection limit, defined by the relation $3 S_{b} / m$ (where $S_{\mathrm{b}}$ represents the standard deviation on the blank and $m$ the slope on the calibration graph) as the analyte concentration yielding such smallest detectable signal (Ghoneim et al., 2000) was estimated to $0.65 \mu \mathrm{M}$. This demonstrates that GCE/MtH-NH 2 can be exploited for the electroanalysis of $\mathrm{CT}$ in aqueous media in the $\mu \mathrm{M}$ range. The analytical performance of GCE/MtH-NH 2 electrode is comparable or better than some data reported in previous literature as shown in Table 1. A relative standard deviation (RSD) of $3.1 \%$ for parallel detections of 0.1 mM CT using five distinct electrodes (see Fig. S5 in Supplementary data) was obtained, indicating a good reproducibility and repeatability of the modified electrode. The anodic peak current of CT lost $4.6 \%$ of its initial value, after 5 consecutive DPV measurements on the same electrode and in the same conditions. This result shows that the proposed electrode is mechanical stable and reliable for the determination of CT. The performance of the method proposed herein is comparable, and even better than some data already reported on the quantification of CT using other modified electrodes (Figueiredo et al., 2007; Sun et al., 2008; Li et al., 2009; Zhu et al., 2009).

\section{(Figure 10 near here)}

\section{(Table 1 near here)}

\subsection{Interference of some organic molecules and real samples analysis}

The effect of potential interfering molecules including hydroquinone, ascorbic acid, dopamine, citric acid, uric acid, D-glucose and quercetin on the DPVs response of CT has been studied. The results obtained are presented in Table 2. The tolerance limit was defined as the concentration ratio of the additive over CT causing less than $5.0 \%$ relative error. Each interfering species was added in the supporting electrolyte in a concentration 5-fold higher than CT concentration. The results obtained showed that the oxidation peak of CT is greatly affected by the presence of hydroquinone, ascorbic acid and quercetin. Catechol and hydroquinone are two isomers of phenolic compounds. The broad DPV response obtained at the GCE/MtH-NH 2 indicated a very tiny sign of multiple components that were not easily 
separated. However, the selectivity of the proposed sensor was evidenced by the neglected responses toward interfering species, by considering the tolerance limit defined earlier.

\section{(Table 2 near here)}

The proposed method was applied to the determination of CT in one tea sample. In this experiment, the concentration of CT was calculated using the standard addition method. The concentration of CT in tea sample was $0.851 \mathrm{mg} \cdot \mathrm{g}^{-1}$. The detection of CT was also evaluated for the analysis of tap and lake water samples after filtering with a Whatman paper (diameter: $125 \mathrm{~mm}$ ). In DPV, no signal of CT was detected in the natural (non-spiked) water samples when using GCE/MtH-NH 2 , indicating that their CT contents were below the detection limit $(0.65 \mu \mathrm{M})$. Therefore, recovery experiments were performed by measuring the DPV responses from samples to which known concentrations of CT were added. The quantitative results are summarized in Table 3. Recovery percentages of more than $110 \%$ obtained in the case of lake water are due to intensive agricultural activities around the lake where other organic compounds are found upon leaching. Yet, the amino groups on the organoclay has high affinity with many biomolecules, a fact that could explain such a result.

\section{(Table 3 near here)}

\section{Conclusion}

The aim of this work was to develop a voltammetric sensor based on amino-montmorillonite and apply it to the detection of catechol. [3(2-aminoethyl)]propyl groups were grafted onto the surface of Na-montmorillonite and acid-activated montmorillonite clays. The results of the analyses by infrared spectroscopy, X-ray diffraction and EIS confirmed the effectiveness of the grafting process. It was demonstrated by CV and DPV that the detection of CT is improved when using the aminated montmorillonite $\left(\mathrm{MtH}-\mathrm{NH}_{2}\right)$ obtained after acid activation, in comparison to the bare glassy carbon electrode. With DPV, the peak current of GCE/MtH-NH $\mathrm{N}_{2}$ was 1.71-fold greater than signal obtained on the bare GCE. After optimization of the factors affecting the accumulation/detection steps, the proposed method was applied to the detection of catechol in real water samples and in a commercial tea sample. 
504

505

506

507

508

509

510

511

512

513

514

515

516

517

518

519

520

521

522

523

524

525

526

527

528

529

530

531

532

533

534

535

536

537

Financial support from UNESCO and The World Academy of Sciences for the Advancement of Science in Developing Countries (RGA 19-257 RG/CHE/AF/AC_G-FR3240310134 awarded to I.K. Tonle) is gratefully acknowledged. A.T. Kamdem (Dr. A. Osorio Group, University of Freiburg, Germany) and G. Doungmo (Prof Dr H. Terraschke Group, ChristianAlbrechts-Universität zu Kiel, Germany) are thanked for facilitation in samples analyses.

\section{References}

Amarasinghe, P.M., Katti, K.S., Katti, D.R., 2008. Molecular hydraulic properties of montmorillonite: a polarized Fourier transform infrared spectroscopic study. Appl. Spectrosc. 62(12), 1303-1313.

Angela de Mello F.G., Virginia S.T.C., Wander L.V., 2009. Smectite organofunctionalized with thiol groups for adsorption of heavy metal ions. Appl. Clay Sc. 42, 410-414.

Aziz, M.A., Selvaraju, T., Yang, H., 2007. Selective determination of catechol in the presence of hydroquinone at bare indium tin oxide electrodes via peak-potential separation and redox cycling by hydrazine. Electroanalysis 19, 1543-1546.

Biernacka, K.I., Silva, A.R., Carvalho, A. P., Pires, J., Freire, C., 2005. Organo-laponites as novel mesoporous supports for Manganese(III) salen catalysts. Langmuir 21(23), 10825-10834.

Celis, R., Hermosin, M.C., Cornejo, J., 2000. Heavy metal adsorption by functionalized clays. Environ. Sci. Technol. 34, 4593-4599.

Chambers, J.Q., (Eds.), 1988. The Chemistry of quinonoid compounds, in: S. Patai, Z. R. (Eds.), Wiley \& Sons, volume 2, New York, pp 719.

Ding, Y.P., Liu, W.-L., Wu, Q.-S., Wang, X. G., 2005. Direct simultaneous determination of dihydroxybenzene isomers at C-nanotube-modified electrodes by derivative voltammetry. J. Electroanal. Chem. 575, 275-280.

Fekadu, M., Mesfin, R., Merid, T., Esayas, A., 2013. Electrochemical determination of catechol in tea samples using anthraquinone modified carbon paste electrode. Nat. Sci. 5(8), 888-894.

Figueiredo, E.C., Tarley, C.R.T., Kubota, L.T., Rath, S., Arrud, M.A.Z., 2007. Online molecularly imprinted solid phase extraction for the selective spectrophotometric determination of catechol. Microchem. J. 85, 290-296.

Fitch, A., 1990. Clay-modified electrodes: a review, Clays Clay Miner. 38, 391-400.

Gaber, A.M.M., 2009. Electrochemical sensor for voltammetric determination of catechol based on screen printed graphite electrode. Int. J. Elechem. Sci. 4, 1167-1177.

Ghoneim, M.M., Hassanein, A.M., Hammam, E., Beltagi, A.M., 2000. Simultaneous determination of $\mathrm{Cd}, \mathrm{Pb} \mathrm{Cu}, \mathrm{Sb}, \mathrm{Bi}, \mathrm{Se}, \mathrm{Zn}, \mathrm{Mn}, \mathrm{Ni}, \mathrm{Co}$ and $\mathrm{Fe}$ in water samples by differential pulse stripping voltammetry at a hanging mercury drop electrode. Fresenius J. Anal. Chem. 367, 378-383. 
Guggenheim, S., Martin, R.T., 1995. Definition of clays and clay minerals: Joint of AIPEA and CMS nomenclature Committees. Clay Miner. 30(3), 257-259.

Hirakawa, K., Oikawa, S., Hiraku, Y., Hirosawa, I., Kawanishi, S., 2002. Catechol and hydroquinone have different redox properties responsible for their differential DNA-damaging ability. Chem. Res. Toxicol. 15, 76-82.

Katti, K.S., Katti, D.R., 2006. Relationship of swelling and swelling pressure on silica-water interactions in montmorillonite. Langmuir 22(2), 532-537.

Kong, Y., Chen, X., Wang, W., Chen, Z., 2011. A novel palygorskite modified carbon paste amperometric sensor for catechol determination. Anal. Chim. Acta 688, 203-207.

Li, M.G., Ni, F., Wang, Y.L., Xu, S.D., Zhang, D.D., 2009. Sensitive and facile determination of catechol and hydroquinone simultaneously under coexistence of resorcinol with a $\mathrm{Zn} / \mathrm{Al}$ layered double hydroxide film modified glassy carbon electrode. Electroanalysis 21, 1521-1526.

Lin, H., Gan, T., Wu, K., 2009. Sensitive and rapid determination of catechol in tea samples using mesoporous Al-doped silica modified electrode. Food Chem. 113,701-704.

Lu, L., Zhang, L., Zhang, X., Huan, S., Shen, G., Yu, R., 2010. A novel tyrosinase biosensor based on hydroxyapatite-chitosan nanocomposite for the detection of phenolic compounds. Anal. Chim. Acta 665,146-151.

Marrubini, G., Calleri, E., Coccini, T., Castoldi, A.F., Manzo, L., 2005. Direct analysis of phenol, catechol and hydroquinone in human urine by coupled-column HPLC with fluorimetric detection. Chromatographia 62, 25-31.

Mendelovici, E., 1973. Infrared study of attapulgite and HC1 treated attapulgite, Clays Clay Miner. 21, 115-119.

Mercier, L., Detellier C., 1995. Preparation, characterization and applications as heavy metals sorbents of covalently grafted thiol functionalities on the interlamelar surface of montmorillonite. Environ. Sci. Technol. 29(5), 1318-1323.

Moldoveanu, S.C., Kiser, M., 2007. Gas chromatography/mass spectrometry versus liquid chromatography/fluorescence detection in the analysis of phenols in mainstream cigarette smoke. J. Chromatogr. A. 1141(1), 90-97.

Montserrat, C.P., Xavier, M.B., Carole, C.B., Marty, J.M., 2010. Diazonium-functionalized tyrosinase-based biosensor for the detection of tea polyphenols. Microchim. Acta 171,187-193.

Nagaraja, P., Vasantha, R.A., Sunitha, K.R., 2001. A sensitive and selective spectrophotometric estimation of catechol derivatives in pharmaceutical preparations. Talanta 55(6), 1039-1046.

Nurchi, V.M., Pivetta, T., Lachowicz, J.I., Crisponi, G., 2009. Effect of substituents on complex stability aimed at designing new iron(III) and aluminum(III) chelators. J. Inorg. Biochem. 103(2), 227-236.

Ozoner, S.K., Yalvac, M., Erhan, E., 2010. Flow injection determination of catechol based on polypyrrole-carbon nanotube-tyrosinase biocomposite detector. Curr. Appl. Phys. 10, 323-328. 
Park, M., Shim, I.K., Jung, E.Y., Choy, J.H., 2004. Modification of external surface of laponite by silanegrafting. J. Phys. Chem. Solids 6(2), 499-501.

Piscitelli, F., Posocco, P., Toth, R., Fermeglia, M., Pricl, S., Mensitieri, G., Lavorgna, M., 2010. Sodium montmorillonite silylation: unexpected effect of the aminosilane chain length. J. Colloid Interface Sci. 351, 108-115.

Qin, Z., Yuan, P., Zhu J., He H., liu D., Yang S., 2010. Influences of thermal pretreatment temperature and solvent on the organosilane modification of $\mathrm{Al}_{13}$-intercalated/Al-pillared montmorillonite. Appl. Clay Sci. 50 (4), 546-553.

Rodriguez, V.M.A., Gonzalez, L.J.D., Munoz, B.M.A., 1994. Acid activation of a Spanish sepiolite: physicochemical characterization, free silica content and surface area of products obtained. Clay Miner. 29, 361-367.

Shan, D., Zhang, J., Xue, H.-G., Zhang, Y.-C., Cosnier, S., Ding, S.-N., 2009. Polycrystalline bismuth oxide films for development of amperometric biosensor for phenolic compounds. Biosens. Bioelectron. 24, 3671-3676.

Shih, Y., Zen, J.M., Kumar, A.S., Chen, P.-Y., 2004. Flow injection analysis of zinc pyrithione in hair care products on a cobalt phthalocyanine modified screen-printed carbon electrode. Talanta 62(5), 912-917.

Suarez B.M., Flores G.L.V., Vicente R.M.A., Martin J.M.P., 1995. Acid activation of a palygorskite with $\mathrm{HCl}$ : development of physico-chemical, textural and surface properties, Appl. Clay Sci. $10,247-258$.

Su, L.N., Qi T., Hongping H., Jianxi Z., Peng Y., 2012. Locking effect: A novel insight in the silylation of montmorillonite surfaces. Mater. Chem. Phys. 136(2-3), 292-295.

Sun, W., Li Y.Z., Yang, M.X., Li, J., Jiao, K., 2008. Application of carbon ionic liquid electrode for the electrooxidative determination of catechol. Sens. Actuator B-Chem. 133, 387-392.

Temerk, Y.M., Ibrahim, H.S.M., Sch

uhmann, W., 2006. Cathodic adsorptive stripping voltammetric determination of the antitumor drug rutin in pharmaceuticals, human urine and blood serum. Microchim. Acta153, 7-13.

Tonle, I.K, Ngameni, E., Walcarius, A., 2004. From clay to organoclay film modified electrodes: tuning charge selectivity in ion exchange voltammetry. Electrochim. Acta 49, 3435-3443.

Tonle, I.K., Ngameni, E., Tchieno, F.M.M., Walcarius A., 2015. Organoclay-modified electrodes: preparation, characterization and recent electroanalytical applications. J. Solid State Electrochem. 19, 1949-1973.

Tonle, K.I., Ngameni, E., Njopwouo, D., Carteret, C., Walcarius A., 2003. Functionalization of natural smectite-type clays by grafting with organosilanes: physico-chemical characterization and application to mercury (II) uptake. Phys. Chem. Chem. Phys. 5, 4951- 496. 
Tonle, K.I., Ngameni, E., Walcarius, A., 2005. Preconcentration and voltammetric analysis of mercury(II) at a carbon paste electrode modified with natural smectite-type clays grafted with organic chelating groups. Sens. Actuator B-Chem. 110, 195-203.

Unnikrishnan, B., Ru, P.L., Chen, S.M., 2012. Electrochemically synthesized Pt-MnO 2 composite particles for simultaneous determination of catechol and hydroquinone. Sens. Actuator B-Chem. $169,235-242$.

Van Olphen. H., Fritpiat. J.J., Data handbook for clay materials and other non-metallic minerals. Pergamon Press. 1979.

Wang, G., He, X., Zhou, F., Li, Z., Fang, B., Zhang, X., Wang, L., 2012. Application of gold nanoparticles $/ \mathrm{TiO}_{2}$ modified electrode for the electrooxidative determination of catechol in tea samples. Food Chem. 135, 446-451.

Wang, Z., Li, S.L.Q., 2007. Simultaneous determination of dihydroxybenzene isomers at single-wall carbon nanotube electrode. Sens. Actuator B-Chem. 127,420-425.

Xie, T., Liu, Q., Shi, Y., Liu, Q., 2006. Simultaneous determination of positional isomers of benzenediols by capillary zone electrophoresis with square wave amperometric detection. J. Chromatogr. A 1109, 317-321.

Xue, A., Zhou, S., Zhao, Y., Lu, X., Han P., 2011. Effective $\mathrm{NH}_{2}$-grafting on attapulgite surfaces for adsorption of reactive dyes. J. Hazard. Mater. 194, 7-14.

Yang, P., Zhu, Q.Y., Chen, Y.H., Wang, F.W., 2009. Simultaneous determination of hydroquinone and catechol using poly(p-aminobenzoic acid) modified glassy carbon electrode. J. Appl. Polym. Sci. 113, 2881-2886.

Yongqing, L., Jian, L., Yanjun, Z., 2017. Poly(sulfosalicylic acid)/multi-walled carbon nanotube modified electrode for the electrochemical detection of catechol. Int. J. Electrochem. Sci. 12, 9512-9522.

Yuan, X., Yuan, D., Zeng, F., Zou, W., Tzorbatzoglou, F., Tsiakaras, P., Wang Y., 2013. Preparation of graphitic mesoporous carbon for the simultaneous detection of hydroquinone and catechol. Appl. Catal. B Environ. 129, 367-374.

Yue, X., Pang, S., Han, P., Zhang, C., Wang, J., Zhang, L., 2013. Carbon nanotubes/carbon paper composite electrode for sensitive detection of catechol in the presence of hydroquinone. Electrochem. Comm. 34, 356-359.

Zhao, D.-M., Zhang, X.-H., Feng, L.-J., Jia, L., Wang, S.-F., 2009. Simultaneous determination of hydroquinone and catechol at PASA/MWNTs composite film modified glassy carbon electrode. Colloids Surf B: Biointerfaces 74,317-321.

Zhao, Y., Song, X., Song, Q., Yin, Z., 2012. A facile route to the synthesis copper oxide/reduced graphene oxide nanocomposites and electrochemical detection of catechol organic pollutant. Cryst. Eng. Comm. 14, 6710-6719. 


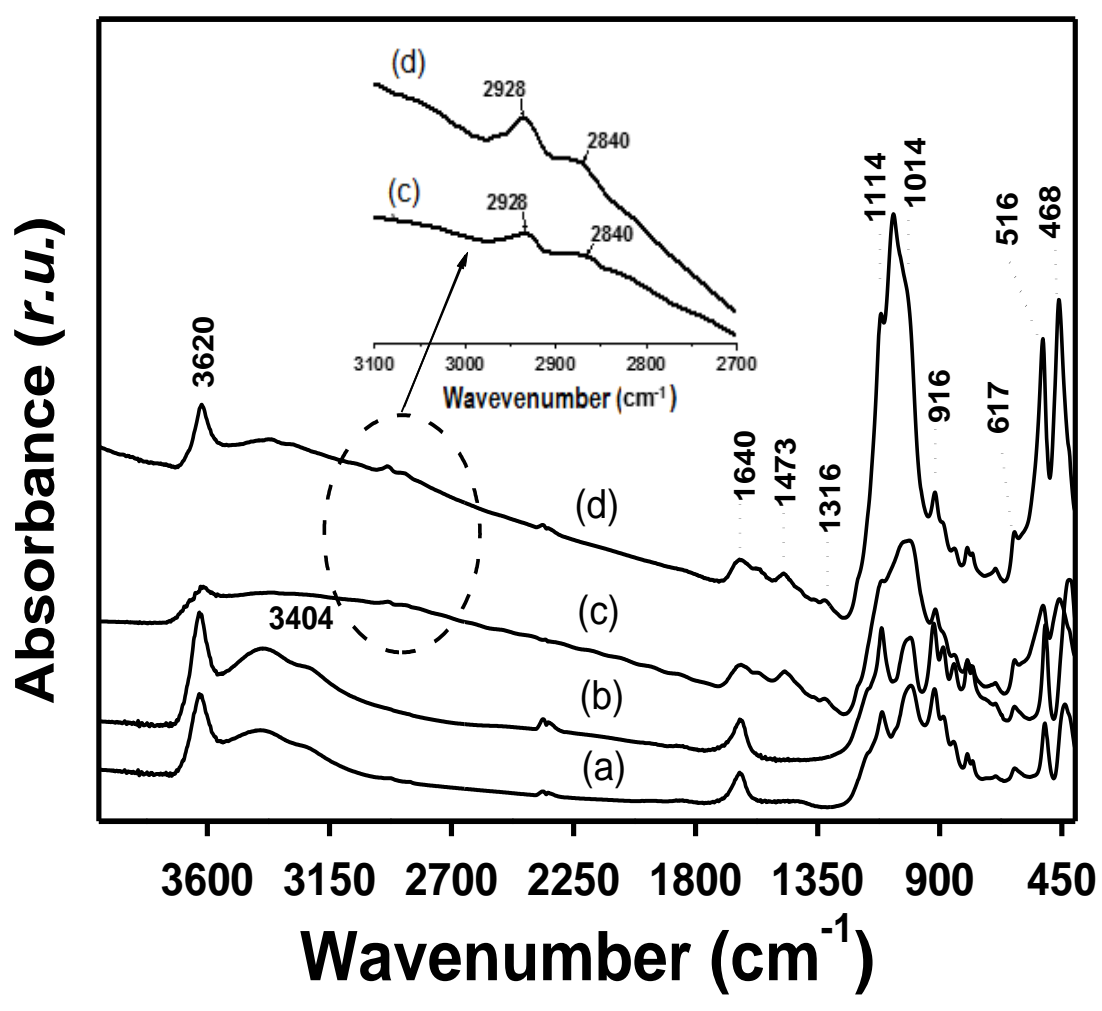

667

668

669

670

671

Figure 1

672 
677

678

679

680

681

682

683

684

685

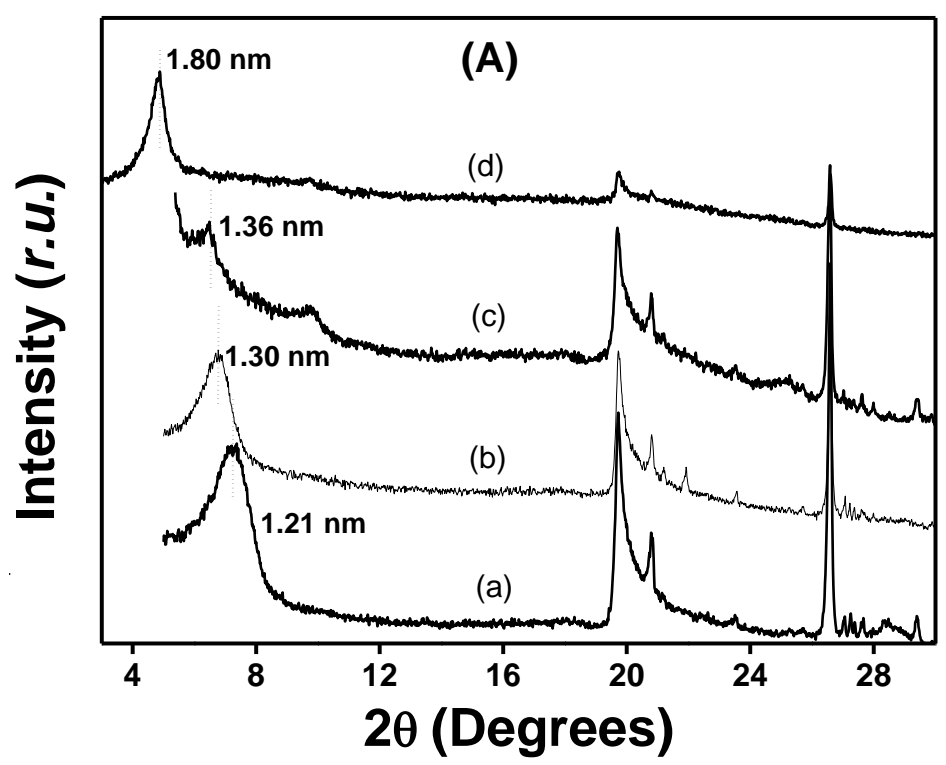

686

687

688

689

690

691

692

693

694

695

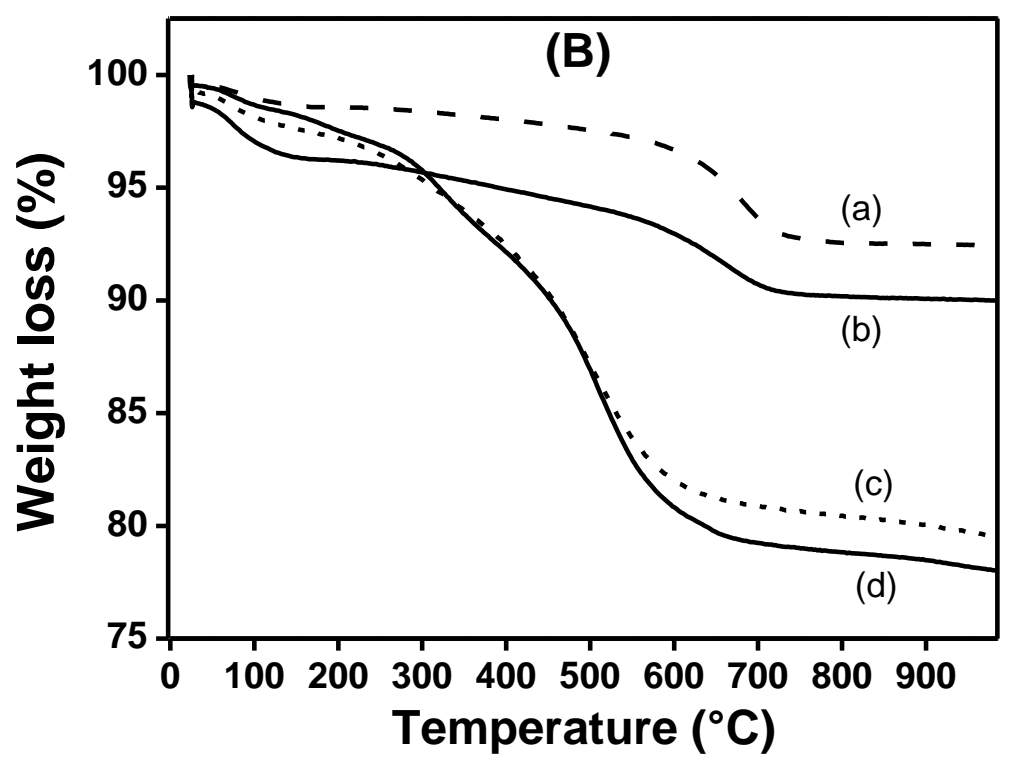

696

697

Figure 2

698

699

700 

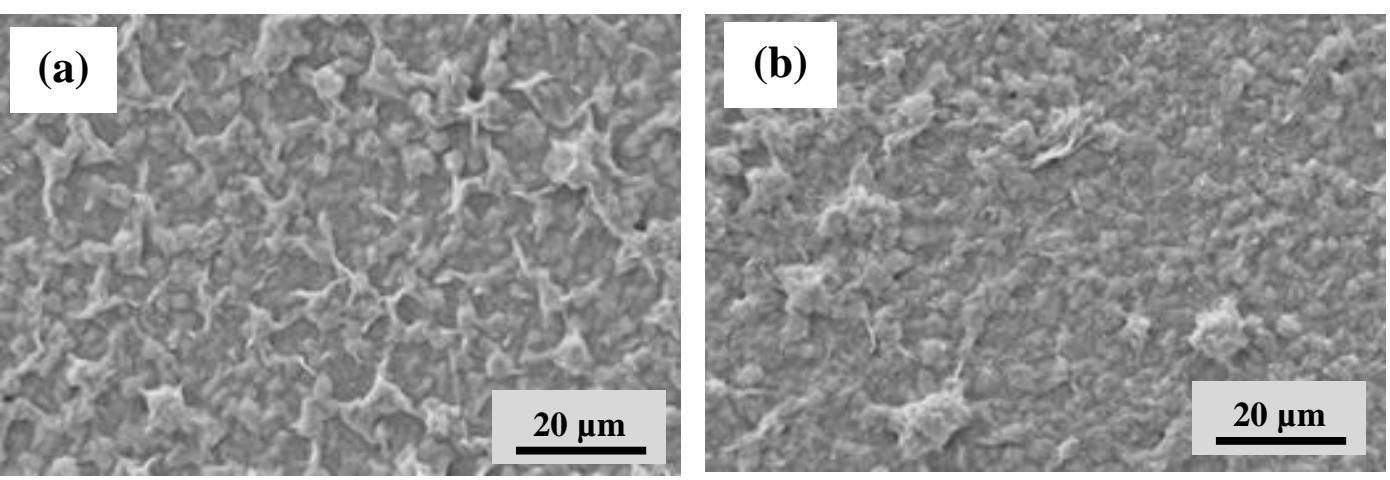

713

714

(c)

715

716

717

718

719

$20 \mu \mathrm{m}$

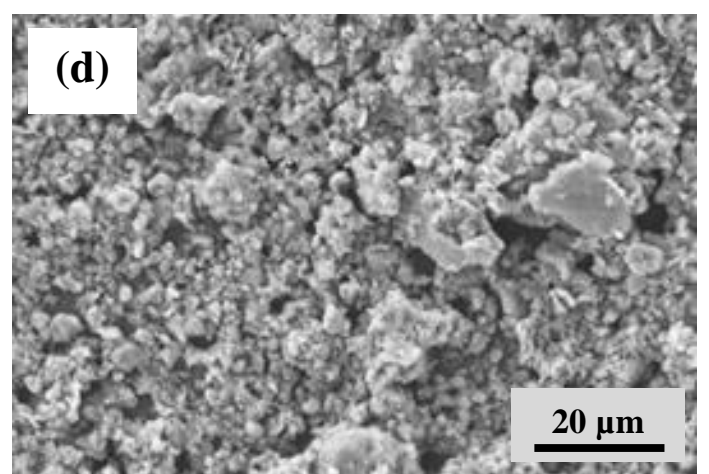

720

721

722

723

724

725

726

727

Figure 3

728

729

730 


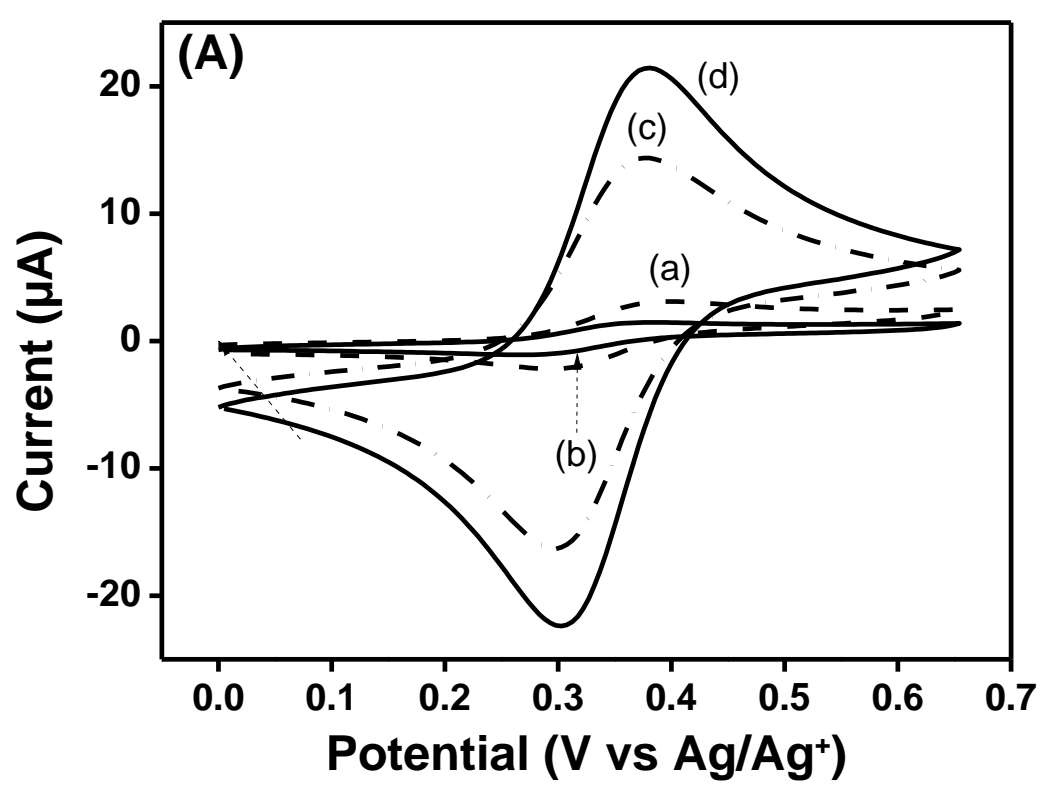

742

743

744

745

746

747

748

749

750

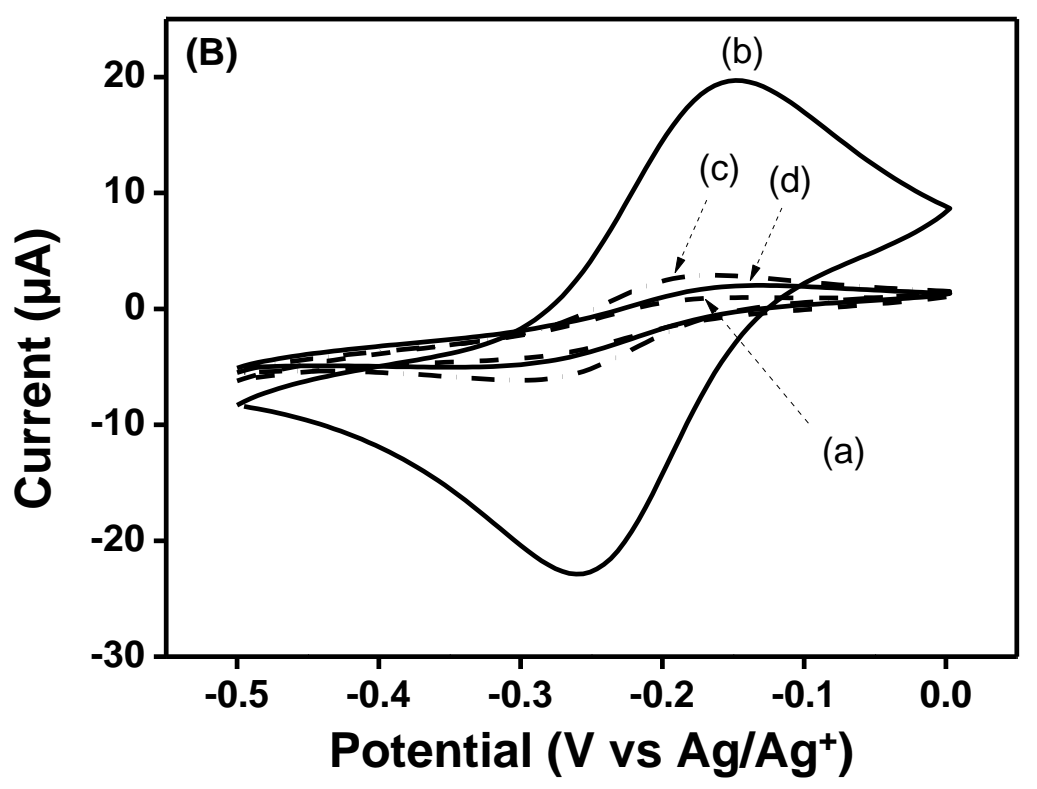

751

752 
762

763

764

765

766

767

768

769

770

771

772

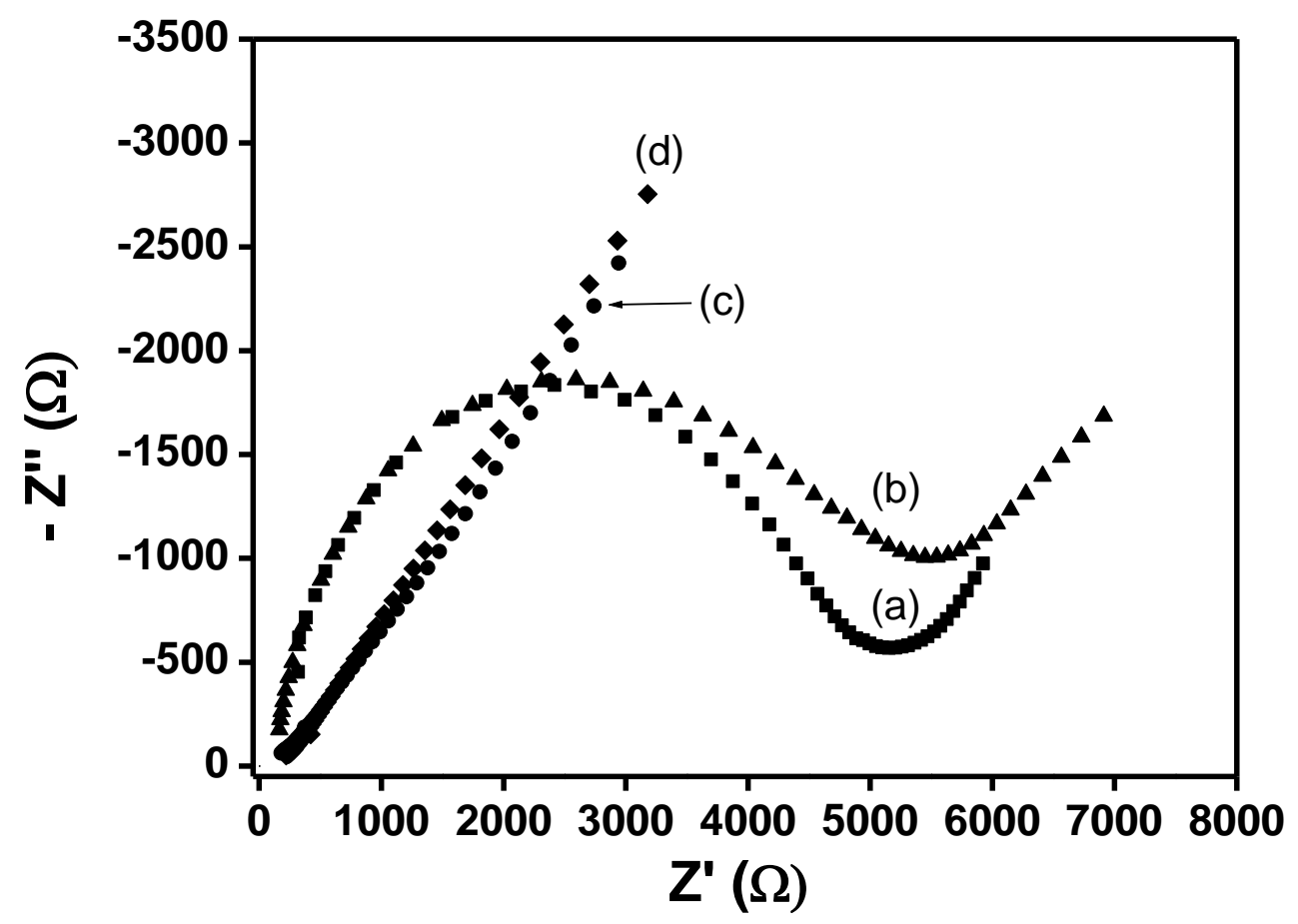

773

774

775

776

777

778

Figure 5

779

780

781

782

783

784 


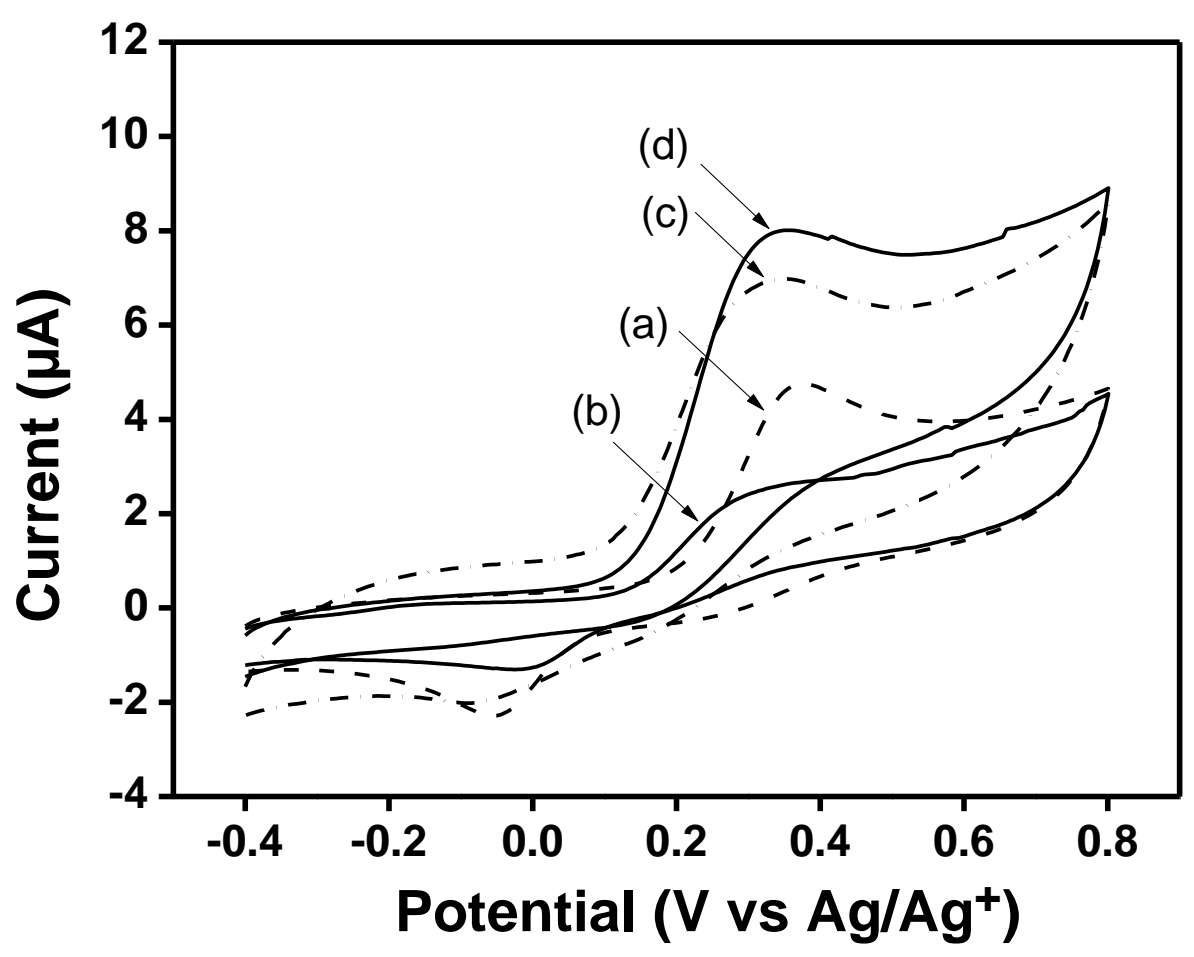



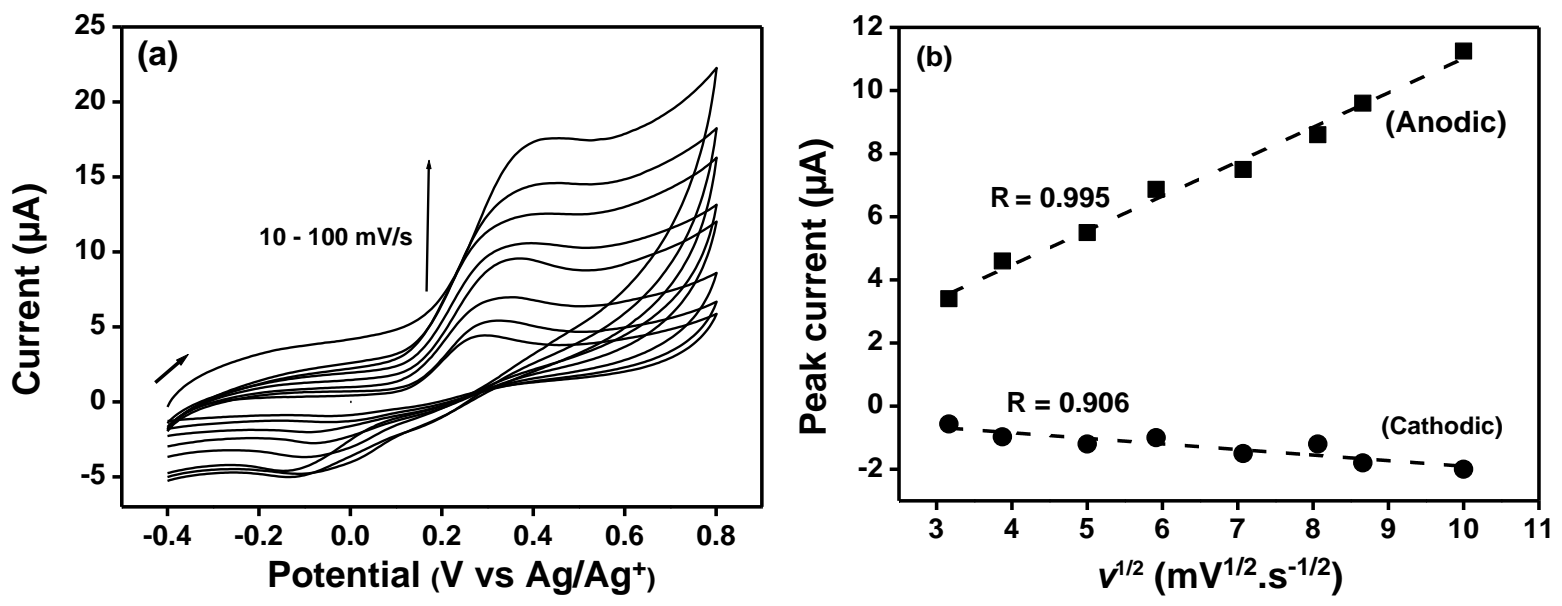

812

813

814

815

816

817

818

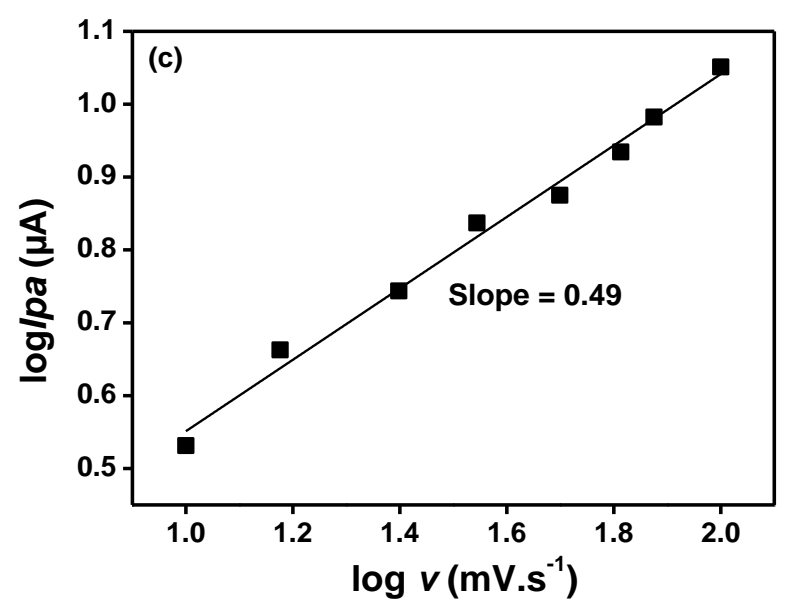

819

820

821

822

823

824

Figure 7

825 


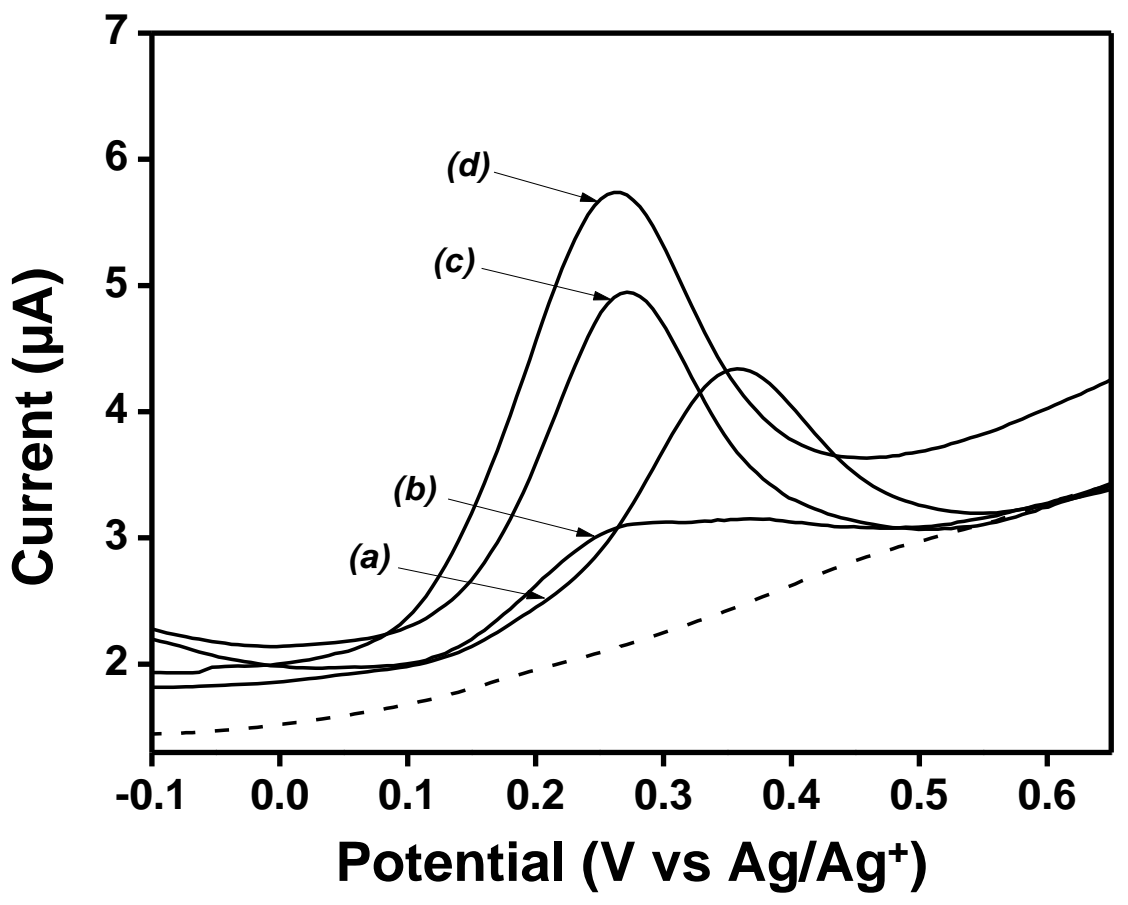

843

844

845

846

847

848

849

850

Figure 8

851

852 
855

856

857

858

859

860

861

862

863

864

865

(a)

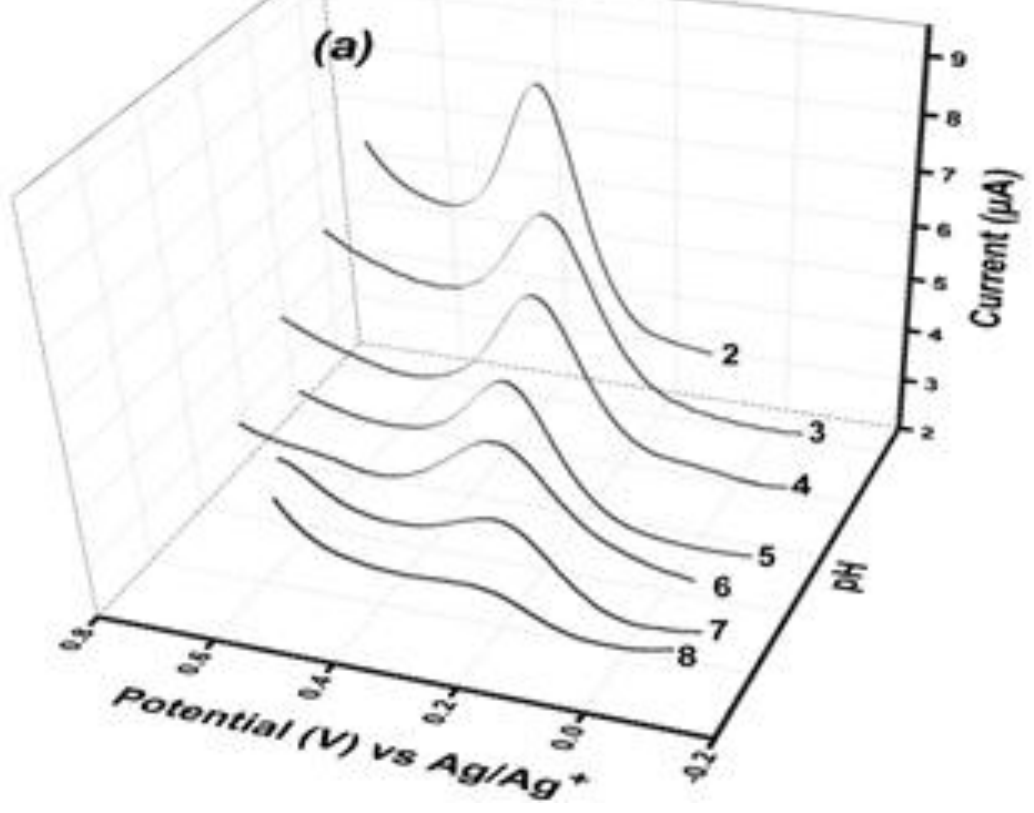

866

867

868

869

870

871

872

873

874

875

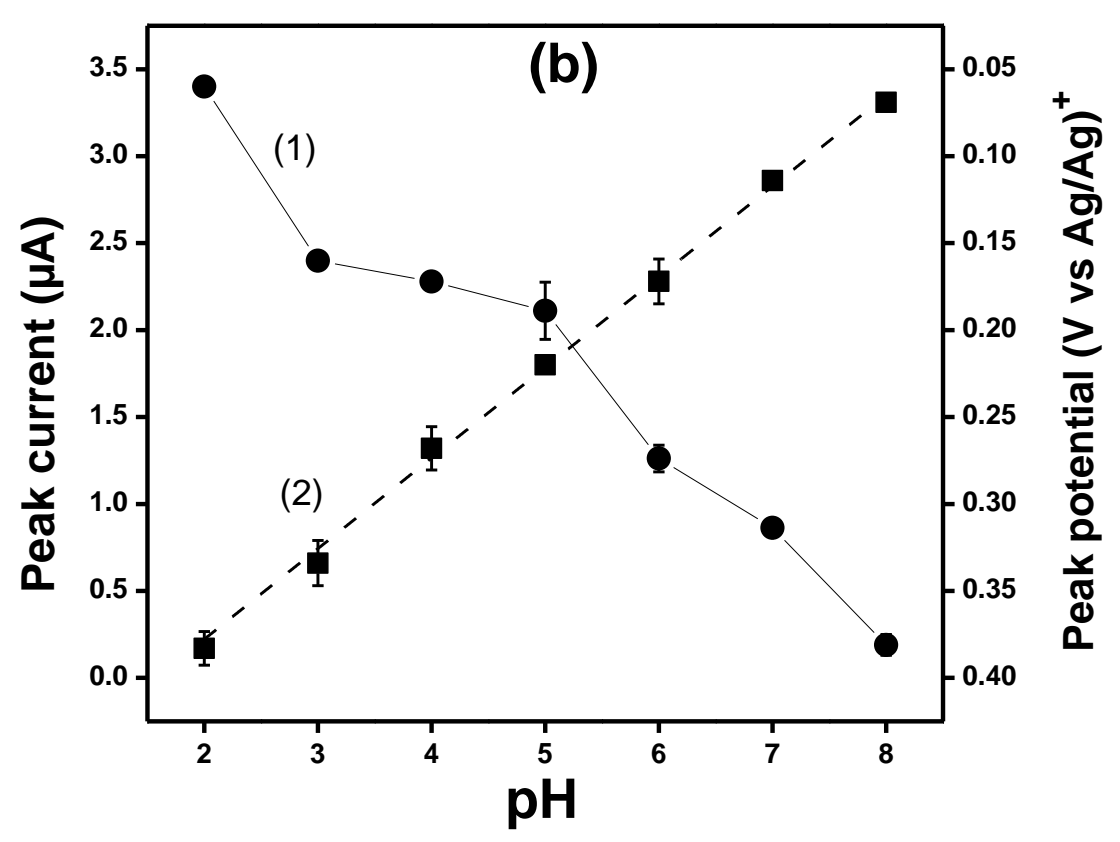

876

877

Figure 9

878

879

880 


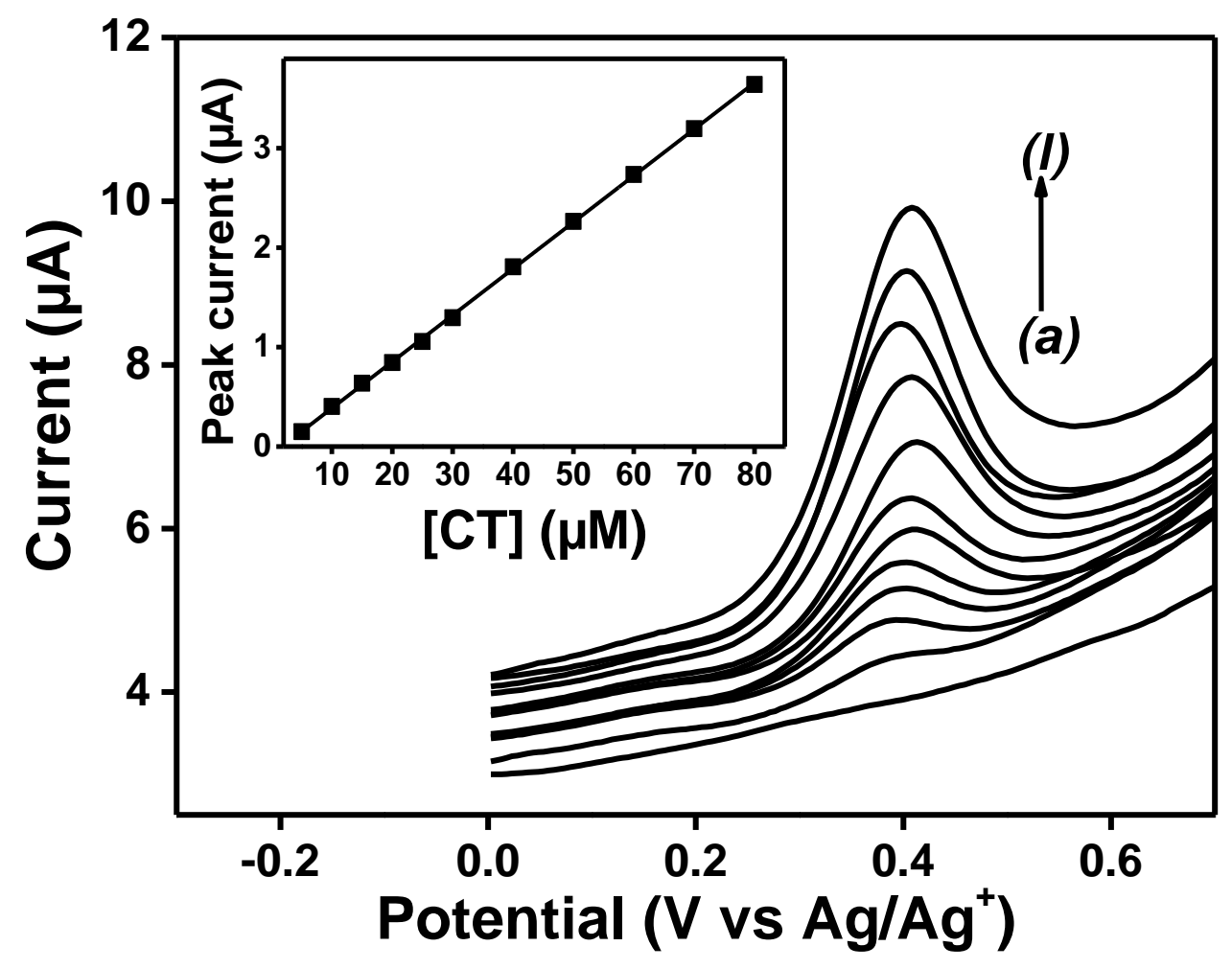

887

888

889 
897

Fig. 1. Infrared spectra of raw (a): $\mathrm{Mt}-\mathrm{Na}$, (b): $\mathrm{MtH}$, (c): $\mathrm{Mt}-\mathrm{NH}_{2}$ and (d): $\mathrm{MtH}-\mathrm{NH}_{2}$.

899

900

901

902

903

904

905

906

907

908

909

910

911

912

913

914

915

916

917

918

919

920

921

922

Fig. 2. (A) Powdered X-ray diffraction patterns, and (B) TGA curves of (a): Mt-Na, (b): MtH, (c): $\mathrm{Mt}-\mathrm{NH}_{2}$ and (4): $\mathrm{MtH}-\mathrm{NH}_{2}$.

Fig. 3. SEM micrographs of GCE covered with various films: (a): Mt-Na, (b): MtH, (c): Mt$\mathrm{NH}_{2}$ and (4): $\mathrm{MtH}-\mathrm{NH}_{2}$.

Fig. 4. Cyclic voltammograms recorded in $0.1 \mathrm{M} \mathrm{KCl} / \mathrm{HCl}$ (pH 1) containing (a) $0.5 \mathrm{mM}$ $\left[\mathrm{Fe}(\mathrm{CN})_{6}\right]^{3-}$ and (b) $0.5 \mathrm{mM}\left[\mathrm{Ru}\left(\mathrm{NH}_{3}\right)_{6}\right]^{3+}$, using various electrodes: (a) Bare GCE, (b) GCE/Mt-Na, (c) GCE/Mt-NH $\mathrm{N}_{2}$ and (d) GCE/MtH-NH ${ }_{2}$. The scan rate was $20 \mathrm{mV} . \mathrm{s}^{-1}$

Fig. 5. EIS spectra in $5 \mathrm{mM}\left[\mathrm{Fe}(\mathrm{CN})_{6}\right]^{3-/ 4-}$ with $0.1 \mathrm{M} \mathrm{KCl}$ at various electrodes; (a): bare GCE, (b): GCE/Mt-Na, (c): GCE/Mt-NH $\mathrm{NH}_{2}$ and (d): GCE/MtH-NH $\mathrm{N}_{2}$. Amplitude of the applied wave potential: $5 \mathrm{mV}$.

Fig. 6. Cyclic voltammograms recorded at $50 \mathrm{mV} . \mathrm{s}^{-1}$ for $0.2 \mathrm{mM}$ CT in $0.1 \mathrm{M}$ BRB solution (pH 4) on (a): bare GCE, (b): GCE/Mt-Na, (c): GCE/Mt-NH $\mathrm{NH}_{2}$ and (d): GCE/ MtH-NH

Fig. 7. (a) Cyclic voltammograms recorded for $0.2 \mathrm{mM} \mathrm{CT}$ in $0.1 \mathrm{M}$ BRB solution (pH 4) on GCE/MtH-NH $\mathrm{N}_{2}$ at different scan rates $\left(10,15,25,35,50,65,75\right.$ and $\left.100 \mathrm{mV} \cdot \mathrm{s}^{-1}\right)$, (b) Peak current as a function of $\mathrm{v}^{1 / 2}$ and (c) $\log (\operatorname{Ip} a)$ as a function of $\log (v)$.

Fig. 8. DPVs of $0.1 \mathrm{mM}$ CT recorded in $0.1 \mathrm{M} \mathrm{BRB}$ solution (pH 4) on (a): bare GCE, (b): GCE/Mt-Na, (c): GCE/Mt-NH $\mathrm{NH}_{2}$ and (d): GCE/MtH-NH 2 (c). Accumulation time: $5 \mathrm{~s}$. The dot line represents the signal of the bare GCE in blank solution.

Fig. 9. (a) DPV curves of $0.1 \mathrm{mM} \mathrm{CT}$ (obtained in triplicate) in $0.1 \mathrm{M}$ BRB solution on $\mathrm{GCE} / \mathrm{MtH}-\mathrm{NH}_{2}$ at various $\mathrm{pH}$; (b) effect of $\mathrm{pH},(1)$ : on the peak current and (2): on the peak potential. Accumulation time: $5 \mathrm{~s}$.

Fig. 10. DPV curves recorded under optimized conditions in $0.1 \mathrm{M}$ BRB solution ( $\mathrm{pH}$ 2) on GCE/MtH-NH $\mathrm{N}_{2}$ for different concentrations of CT (a-1): 5, 10, 15, 20, 25, 30, 40, 50, 60, 70 and $80 \mu \mathrm{M}$. Accumulation time: 30 s. Inset shows the corresponding calibration graph. 